\title{
Low Dose T1W DCE-MRI for Early Time Points (ET) Perfusion Measurement in Patients with Intra-Cranial Tumors: A Pilot Study Applying the Microsphere Model to Measure Absolute Cerebral Blood Flow
} DOI:

10.1002/jmri.25979

\section{Document Version}

Accepted author manuscript

Link to publication record in Manchester Research Explorer

\section{Citation for published version (APA):}

Li, K-L., Lewis, D., Jackson, A., Zhao, S., \& Zhu, X. (2018). Low Dose T1W DCE-MRI for Early Time Points (ET) Perfusion Measurement in Patients with Intra-Cranial Tumors: A Pilot Study Applying the Microsphere Model to Measure Absolute Cerebral Blood Flow. Journal of Magnetic Resonance Imaging. https://doi.org/10.1002/jmri.25979

Published in:

Journal of Magnetic Resonance Imaging

\section{Citing this paper}

Please note that where the full-text provided on Manchester Research Explorer is the Author Accepted Manuscript or Proof version this may differ from the final Published version. If citing, it is advised that you check and use the publisher's definitive version.

\section{General rights}

Copyright and moral rights for the publications made accessible in the Research Explorer are retained by the authors and/or other copyright owners and it is a condition of accessing publications that users recognise and abide by the legal requirements associated with these rights.

\section{Takedown policy}

If you believe that this document breaches copyright please refer to the University of Manchester's Takedown Procedures [http://man.ac.uk/04Y6Bo] or contact uml.scholarlycommunications@manchester.ac.uk providing relevant details, so we can investigate your claim.

\section{OPEN ACCESS}




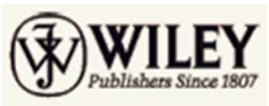

\section{Low Dose T1W DCE-MRI for Early Time Points (ET) Perfusion Measurement in Patients with Intra-Cranial Tumors: A Pilot Study Applying the Microsphere Model to Measure Absolute Cerebral Blood Flow}

\begin{tabular}{|r|l|}
\hline Journal: & Journal of Magnetic Resonance Imaging \\
\hline Manuscript ID & JMRI-17-1192.R2 \\
\hline Wiley - Manuscript type: & Original Research \\
\hline Classification: & $\begin{array}{l}\text { Contrast enhancement techniques }<\text { Imaging Principles and Education }< \\
\text { Basic Science, Contrast enhancement (neuro-imaging) }<\text { Neuro-imaging }< \\
\text { Clinical Science, Contrast enhancement (head and neck) }<\text { Head and neck } \\
\text { imaging }<\text { Clinical Science, Diffusion and perfusion imaging }<\text { Imaging } \\
\text { Principles and Education }<\text { Basic Science, Imaging techniques and } \\
\text { processing < Imaging technology and safety }<\text { Basic Science }\end{array}$ \\
\hline Manuscript Keywords: & $\begin{array}{l}\text { Low dose gadolinium based contrast agent, cerebral blood flow, dynamic } \\
\text { susceptibility contrast-enhanced MRI, dynamic contrast enhanced MRI, } \\
\text { early time points, intra-cranial tumor }\end{array}$ \\
\hline
\end{tabular}

\section{SCHOLARONE ${ }^{m}$}

Manuscripts 


\title{
Low Dose T1W DCE-MRI for Early Time Points (ET) Perfusion Measurement in Patients with Intra-Cranial Tumors: A Pilot Study Applying the Microsphere Model to Measure Absolute Cerebral Blood Flow
}

\begin{abstract}
BACKGROUND:

Previous studies have measured cerebral blood flow (CBF) with DSC-MRI using an “early time points" (ET) method based on microsphere theory.

PURPOSE:

To develop and assess a new ET method for absolute CBF estimation using low-dose high-temporal (LDHT) T1W-DCE-MRI.
\end{abstract}

STUDY TYPE:

Retrospective cohort study

SUBJECTS:

Seven patients with sporadic vestibular schwannoma (VS) who underwent test-retest imaging; one patient with glioblastoma multiforme (GBM) imaged pre-treatment; and twelve neurofibromatosis type 2 (NF2) patients undergoing bevacuzimab treatment, imaged pre- and 90 days post-treatment. 


\title{
FIELD STRENGTH/SEQUENCE,
}

LDHT-DCE-MRI was performed at 1.5 and 3.0T, using 3D spoiled gradient echo with phase cycling. DSC-MRI performed in one patient, using 3D echo-shifted multi-shot echo-planar imaging (PRESTO) at 3T.

\begin{abstract}
ASSESSMENT:
Through Monte Carlo simulations, CBF estimation using three newly developed average contrast agent concentration (AC) based methods (ACrPK, ACrMG, ACcomb), was compared against conventional maximum gradient (MG) approaches, at varying Rician noise levels. Reproducibility and applicability of the ACcomb method was assessed in our sporadic-VS/GBM/NF2 patient cohort respectively.
\end{abstract}

\section{STATISTICAL TESTS:}

Reproducibility was measured using test-retest coefficient of variation (CoV). Pre- and post-treatment $\mathrm{CBF}$ values were compared using paired t-test with Bonferroni correction.

\section{RESULTS:}

Monte Carlo stimulations demonstrated that AC-based methods, particularly ACcomb, offered superior accuracy to conventional MG approaches. Overall test-retest CoV using the ACcomb method was 5.76 in normal-appearing white matter (NAWM). The new ACcomb method produced GM/WM CBF estimates in the NF2 patient cohort of $55.9 \pm 13.9 / 25.8 \pm 3.5$ on day 0 ; compared to $155.6 \pm 17.2 / 128.4 \pm 29.1$ for the classical MG method. There was a moderate (10\% using ACcomb and ACrpk) increase in CBF of 
NAWM 90 days post therapy $(\mathrm{P}=0.03$ and 0.005$)$.

\title{
DATA CONCLUSION:
}

Our new AC based method of $\mathrm{CBF}$ estimation offers excellent reproducibility, and displays more accuracy in both Monte Carlo analysis and clinical data application, than conventional MG based approaches.

\begin{abstract}
Keywords: Low dose gadolinium based contrast agent, cerebral blood flow, dynamic susceptibility contrast-enhanced MRI, dynamic contrast enhanced MRI, early time points, intra-cranial tumor
\end{abstract}




\section{INTRODUCTION}

The microsphere method is a classic technique for blood flow quantification, based on the principle that injected labelled particles, which are too big to fit through the capillaries, are delivered to each tissue element in proportion to the local blood flow, and remain trapped there for subsequent counting. While the classical microsphere method is restricted to animal studies, the microsphere mode $^{1-3}$ has become the basis for blood flow quantification in both computed tomography $(\mathrm{CT})^{3-5}$, and perfusion $\mathrm{MRI}^{6-9}$.

The maximum gradient (MG) method for calculation of cerebral blood flow (CBF) is based on the microsphere model and has been widely applied in perfusion $\mathrm{CT}^{3,10}$. Recently, Kwong et al ${ }^{7,11,12}$ proposed a technique utilizing the early data points of the contrast agent $(\mathrm{CA})$ bolus for relative $\mathrm{CBF}(\mathrm{rCBF})$ calculation with dynamic susceptibility contrast (DSC) MRI. They used measurement from early time points before the gadolinium based contrast agent (GBCA) has left the tissue, i.e. the time window which meets the microsphere prerequisite. They named the region of the time course curve that meets the requirements of the microsphere model the "early time points window (ETW)" and the analysis technique the "early time points" (ET) method. They proposed that as long as the microsphere prerequisite is satisfied, different ways of manipulating the early rising bolus concentration time course would theoretically yield the same $\mathrm{rCBF}$ result, but that one method could prove superior to another under specific noise conditions, and that measurement of absolute blood flow could be achieved with sampling of arterial blood from appropriate arteries ${ }^{7,11,12}$. 
The MG method has however, not been broadly accepted in T1 weighted (T1W) dynamic contrast enhanced (DCE) MRI evaluation of $\mathrm{CBF}^{13}$. There are two main reasons for this: Firstly, the use of the MG method in DCE-MRI data requires that the microsphere prerequisite is met $^{7}$ which depends on various factors, including: contrast bolus volume, injection rate and the patient's cardiac output ${ }^{10}$. Secondly, the MG method requires good enhancement-to-noise ratio (ENR, maximal signal change divided by the standard deviation of the baseline of the DCE-MRI), which may not always be met in early timepoint DCE MRI images used to calculate perfusion. The aim of the current study was to therefore develop and assess a new methodology for absolute CBF estimation which uses data derived from a low dose whole brain 3D coverage T1W DCE MRI acquisition, and is based on the microsphere and ET strategies.

\section{MATERIALS AND METHODS}

\section{Patients}

We retrospectively analyzed MRI data from twenty patients, which had been prospectively collected for a previous study using the same T1W DCE MRI protocol. Twelve patients with type 2 neurofibromatosis (NF2), seven patients with sporadic vestibular schwannomas (VS), and one patient with histologically proven glioblastoma multiforme (GBM) were recruited into the study. Ethical approval was in place for the study (NHS Health Research Authority; NRES committee North West 13/NW/0131) and all participants had previously consented for later data analysis of their MRI data.

Amongst the twelve NF2 patient cohort there were 21 vestibular schwannomas and 11 
meningiomas. All twelve patients with NF2 were undergoing treatment with the antiVascular Endothelial Growth Factor antibody, bevacizumab, and underwent imaging on two occasions: pre-treatment (day0) and 3 months (day90) following treatment. The seven patients with sporadic VS cohort were imaged on two separate occasions 4 days apart.

\section{MRI}

The 12 Patients with NF2 and seven patients with sporadic VS were imaged on a 1.5T scanner (Philips Achieva, Best, Netherlands) using an 8-channel head coil. The patient with a GBM was imaged on a 3.0T scanner (Philips Achieva, 3.0TX).

The following scanning protocols were employed: 1) Higher spatial resolution morphological MRI, e.g. high spatial resolution non-enhanced (C-) 3D T1-weighted (T1W) MRI to support tissue segmentation, and contrast enhanced (C+) T1W gradient echo for extracting tumor enhanced volume. 2) DCE-MRI. Low GBCA dose, high temporal resolution (LDHT) DCE-MRI data were collected as the first part of the dual temporal resolution technique, an improved coverage and spatial resolution-using Dual Injection dynamic Contrast-Enhanced (ICR-DICE), as described previously ${ }^{14}$. Variable flip angle $\left(\alpha=2^{\circ}, 8^{\circ}, 15^{\circ}\right.$ and $\left.20^{\circ}\right)$ acquisitions were performed prior to the LDHT-DCE series for native longitudinal relaxation rate $\left(\mathrm{R} 1_{\mathrm{N}}\right)$ mapping. The LDHT-DCE MRI uses the same 3D GRE sequence with a flip angle of $20^{\circ}$, with an FOV of $240 \times 240 \mathrm{~mm}$, image matrix of $96 \times 96 \times 22$ voxels, sense acceleration factor of 1.8, and temporal 
resolution of $\Delta t=1.0 \mathrm{~s}(\mathrm{n}=300)$ (Fig. 1a). A low dose (fixed volume of $3 \mathrm{ml}, 0.02$ $\mathrm{mmol} / \mathrm{kg}$ depending on body weight) of macrocyclic GBCA (gadoterate meglumine; Dotarem, Geurbet, Roissy, France) was administered by power injector as an intravenous bolus at a rate of $3 \mathrm{ml} / \mathrm{s}$, followed by a chaser of $20 \mathrm{mls}$ of $0.9 \%$ saline administered at the same rate. This LDHT acquisition was then followed by a full GBCA dose $(0.1$ $\mathrm{mmol} / \mathrm{kg}$ ), high-spatial resolution (matrix size of $240 \times 240 \times 70$ ) acquisition (FDHS) DCE MRI. As the name of ICR-DICE indicates, a large acquisition volume covering the whole brain is used in order to eliminate unsaturated flowing spins enter the imaging slab, which can cause undesirable signal enhancement and generate image artifacts. To obtain satisfactory elimination of in-flow artifacts, it is paramount important that (1) the volume coverage of 3D slab is large enough to incorporate the top of the brain, the circle of Willis and the terminations of the internal carotid arteries bilaterally (Fig 1b); (2) The read gradient of the 3D slab is orientated in parallel to the vessels for the maximum saturation of the out slab upstream. 3) For the GBM patient, following the T1W-DCE MRI acquisition, a dynamic susceptibility contrast enhancement imaging (DSC) series was undertaken, using a 3D echo-shifted multi-shot echo-planar imaging (3D PRESTO) ${ }^{15}$. The PRESTO series used scan parameters of TR/TE/flip angle of $20 \mathrm{~ms} / 26.5 \mathrm{~ms} / 10^{\circ}$. The contrast bolus administered for the T1W-DCE MRI acquisitions was used as the preload for leakage correction, and a third injection of $0.1 \mathrm{mmol} / \mathrm{kg}$ of Dotarem followed by a saline flush was administered at the 5th dynamic frame of the 3D PRESTO-DSC. The DSC has an image matrix of $128 \times 128 \times 30$ and $\Delta t$ of $1.5 \mathrm{~s}$.

\section{Image Co-registration and Segmentation}


$\mathrm{SPM}^{16}$ was used for image co-registration and segmentation of the MRI data into GM, WM, and CSF. Three probability maps representing GM, WM and CSF, segmented from the 3D T1W images, were re-aligned and re-sliced to the space of the 3D individual volumes of the DCE-MRI of the subject. WM and GM masks were generated using a probability cutoff of 0.975 , and these masks were then used for subsequent quantitative analysis. Figure $1 \mathrm{~b}$ shows the segmented GM, WM, and tumor mask overlaid on the aligned last frame of the 3D LDHT and FDHS.

\section{Measurement of Vascular Input Function (VIF)}

Estimation of absolute CBF requires identification of a suitable AIF, and for practical purposes, a good approximation may be achieved by measuring the input function in the superior sagittal sinus (SSS) ${ }^{3,17}$. Our VIF measurement method for the T1W LDHT data has been previously described and utilizes a semi-automatic extraction method, to identify voxels within the SSS that display maximum enhancement during the first pass of the CA bolus ${ }^{18}$.

\footnotetext{
In order to investigate variations in the shape of VIFs from individually measured $C_{\mathrm{b}}(t)$ curves we retrospectively inspected VIFs from all previous LDHT T1W DCE MRI studies performed in our laboratory that used the same injection protocol. In total 55 VIFs from 55 visits of 36 patients with NF2 $(n=20)$, sporadic VS $(n=7)$, and GBM $(n=9)$ were analyzed. All participants had consented for later retrospective analysis of their data.
} 
We examined variations in the VIF to identify the range in the number of measurement points that can be identified in the early time points window.

Data from the T2*W DSC acquisition was processed using the commercially available software tool (MIStar, Apollo Medical Imaging, Melbourne, Australia), which incorporates an automated AIF detection algorithm. This algorithm performs pixelwise calculation of bolus arrival time, height, width and area under curve (AUC) of the $\Delta \mathrm{R} 2 *$ signal, and identifies the AIF as the cluster of pixels which show early arrival, large AUC, high peak height and narrow peak width.

\section{The Microsphere Model}

A prerequisite for the application of the microsphere theory is "sufficient organ retention"

${ }^{3}$. In fact, for a time period less than the minimum intravascular transit time, any indicator behaves like a microsphere, in that no indicator that has arrived in an organ will have yet left it. During this time, the organ 'collects' counts, i.e. performs a 'biological' integration of the arterial counts. 'Mathematical' integration of the arterial counts, i.e. a running sum of the frame-by-frame counts, therefore generates a curve which has the same shape as the organ curve ${ }^{2}$. Mathematically, the microsphere model can be written as:

$$
C_{t}(t)=f \cdot \int_{0}^{t} C_{b}\left(t^{\prime}\right) d t^{\prime} \quad \text { with } t \in E T W, \quad[1]
$$


where the tissue GBCA concentration, $C_{t}(t)$, is equal to the amount of GBCA delivered to $1 \mathrm{ml}$ of tissue by time $t, f$ is the perfusion term (usually expressed as $\mathrm{ml}$ minute $\mathrm{ml}^{-1}$ ) $^{2}$ and $\mathrm{C}_{\mathrm{b}}(t)$ is the arterial blood concentration (input function).

Then, according to the fundamental theorem of calculus, we have

$$
\frac{d C_{t}(t)}{d t}=f \cdot C_{b}(t)
$$

and

$$
\max \left(\frac{d C_{t}(t)}{d t}\right)=f \cdot \max \left(C_{b}(t)\right)
$$

Eq. 3 implies that the maximum gradient of the upslope of the first-pass $C_{t}(t)$ is reached at the same time as the regional arterial peak under the microsphere prerequisite:

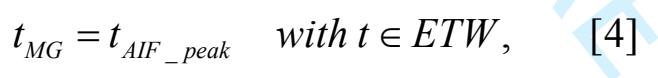

where $t_{\mathrm{MG}}$ and $t_{\mathrm{AIF} \text { _peak }}$ are the time to the maximum gradient of $\mathrm{C}_{\mathrm{t}}(t)$ and the time to the peak of arterial input function (AIF), respectively.

The MG method for blood flow derivation is then expressed as:

$$
f=\max \left(\frac{d C_{t}(t)}{d t}\right) / \max \left(C_{b}(t)\right) .
$$

\section{The New T1W-ET Methods For Absolute CBF Estimation}

The new T1W-ET methods are based on the following two hypotheses: 
I) With a low dose compact bolus, the whole upslope segment prior to the first pass peak of the tissue concentration-time curves can be taken as the early time window (ETW), and the working data range for the CBF measurement.

II) When the effects of noise are considerable, an averaged concentration (AC) based method, especially when applied on data points located in a segment with higher ENR, is superior to a MG based method.

To assess the validity of our low dose T1W DCE MRI protocol for CBF evaluation using the microsphere model, i.e. whether Eq. 1 does hold true for our data, we tested whether the integrated input curve ( $\mathrm{INT}_{\text {aif }}$ ) could be scaled so that it paralleled (or aligned after time shifting) the rising bolus time course of the tissue uptake curve, and if the required scaling factor was within the expected range of the cerebral blood flow $(f)$ for the type of the tissue tested.

The first step of the T1W-ET methods is to identify the first pass peak point of the tissue concentration-time curve, which is the point of maximum enhancement within the $30 \mathrm{~s}$ time period following the bolus arrival time of the global AIF. The two consecutive data points which display the greatest difference in tissue enhancement within the time segment between the AIF bolus arrival and the first pass peak point, are then found. Five different ways of manipulating the rising bolus concentration time course were compared for absolute $\mathrm{CBF}$ evaluation: 
1) The classical maximum gradient (MGclassical) method - the two consecutive data points which display the greatest difference in tissue enhancement on the rising bolus time course are identified. The maximum gradient is calculated as $\left(\Delta \mathrm{C}_{\mathrm{t}}(t)\right)_{\max } / \Delta \mathrm{t}$, and used in Eq [5] to determine CBF.

2) The upslope method (the slope method) - the two data points, $i$ and $i+1$, displaying the greatest difference in enhancement are identified and the slope over these two points and two adjacent points $[i-1, i, i+1, i+2]$ is estimated by linear regression. This slope is then used as the numerator in Eq. [5] for calculating CBF.

The next two methods use the running average of three consecutive data points as the value of $\mathrm{C}_{\mathrm{t}}(t)$ in Eq. [1] for CBF evaluation. Both methods choose a reference time point $\left(t_{\text {ref }}\right)$ other than the time of bolus arrival (TOA), and identify data points located on the upper part of the rising bolus time course (a segment with higher ENR).

3) Averaged concentration referencing $t_{\mathrm{MG}}$ (the ACrMG method), where $t_{\mathrm{MG}}=\left(t_{\mathrm{i}}+\right.$ $\left.t_{i+1}\right) / 2$. The running average of three data points $[i+1, i+2, i+3]$ was used as the value of $\mathrm{C}_{\mathrm{t}}(t)$, therefore $t=t_{\mathrm{i}+2}=t_{\mathrm{MG}}+1.5 \cdot(\Delta t)=t_{\mathrm{AIF} \_ \text {peak }}+1.5 \cdot(\Delta t)$ in Eq. [1]. The value of $t_{\text {AIF_peak }}$ was found from the gamma variant fit of the $C_{\mathrm{b}}(t)$.

4) Averaged concentration referencing $t_{\text {peak }}$ (the ACrPK method), where $t_{\text {peak }}$ was the tissue peak time. If the time point for the tissue peak was $i_{\text {peak }}$, the running average of three data points $\left[\mathrm{i}_{\text {peak }}-1, \mathrm{i}_{\text {peak }}-2, \mathrm{i}_{\text {peak }}-3\right]$ was used as the value of $\mathrm{C}_{\mathrm{t}}(t)$. For 
convenience, we used $t=t_{\mathrm{AIF} \text { peak }}+1.5 \cdot(\Delta t)$ as the upper time limit in integration of AIF, as same as in the ACrMG method.

5) Finally, based on the results from Monte Carlo error analysis of the above four methods, we developed a new method for calculation of the averaged concentration. The new method takes the average of the $\mathrm{CBF}$ values obtained from the ACrMG and ACrPK methods. We called the combined method the ACcomb method.

\begin{abstract}
We denoted the absolute $\mathrm{CBF}$ estimated using the five methods as $\mathrm{T} 1 \mathrm{~W}-\mathrm{CBF}_{\mathrm{ET}}$ which comprises $\mathrm{CBF}_{\mathrm{ACrMG}}, \mathrm{CBF}_{\mathrm{ACrPK}}, \mathrm{CBF}_{\mathrm{ACcomb}}, \mathrm{CBF}_{\mathrm{MGclassical}}$, and $\mathrm{CBF}_{\text {slope, }}$, respectively.
\end{abstract}

\title{
Monte Carlo Simulation For Error Analysis
}

Monte Carlo simulation was used to investigate the effects of noise on the CBF values estimated with the five T1W-ET methods. The WM and GM GBCA concentration curves were simulated based on the microsphere model and the hypothesis that the ETW (i.e., the working data range for the $\mathrm{CBF}$ measurement) is the whole upslope segment prior to the first pass peak of the tissue concentration-time curves.

The synthesized WM and GM contrast agent concentration curves (see below), with 'true' $\mathrm{CBF}_{\mathrm{WM}}=25 \mathrm{ml} / \mathrm{min} / 100 \mathrm{ml}$ and 'true' $\mathrm{CBF}_{\mathrm{GM}}=60 \mathrm{ml} / \mathrm{min} / 100 \mathrm{ml}$ respectively, were converted back into SI-time curves based on the in vivo mean baseline SI, the precontrast $\mathrm{T} 1$ relaxation time $\left(T_{10}\right)$, and a literature value of longitudinal relaxivity (4.39 
$\left.\mathrm{mM}^{-1} \mathrm{~s}^{-1}\right)^{19}$. The generated SI-time courses were sampled with a temporal resolution of 1.0 second, and Rician white noise with noise level (= standard deviation/ mean baseline signal) of $1 \%, 2 \%, 3 \%, 4 \%$ and $5 \%$ respectively was added to the simulated SI-time curves. Absolute CBF values were calculated using the synthetic data sets to produce the so-called 'measured' values with the five estimation methods respectively. Percent deviations (PD) of the 'measured' values from the 'true' values were calculated as: $\mathrm{PD}=$ $($ measured - true $) /$ true $\cdot 100 \% .20000$ repetitions were performed for each method to produce mean and standard deviation (SD) of PD for each CBF estimates.

\title{
In Vivo Data Processing
}

$\mathrm{T} 1 \mathrm{~W}-\mathrm{CBF}_{\mathrm{ET}}$ images were calculated for the 12 NF2 patients, the 7 sporadic VS patients, and for the one patient with a GBM. For the GBM patient, maps of T2*W-CBF and T2*W-CBV were generated from the DSC MRI using MIStar and the singular value decomposition (SVD) deconvolution method of Ostergaard et $\mathrm{al}^{20}$. Previous authors have attempted to use model free deconvolution to analyse T1W DCE data ${ }^{21}$. We therefore also analysed the LDHT DCE-MRI data from our GBM patient using a model free SVD deconvolution approach and compared these derived values with values obtained using the $\mathrm{T} 1 \mathrm{~W}-\mathrm{CBF}_{\mathrm{ET}}$ and $\mathrm{T} 2 * \mathrm{~W}-\mathrm{CBF}$ approaches.

\begin{abstract}
We also carried out a tracer kinetic analysis on the T1W-DCE MRI data using the extended Tofts model (ETM) $)^{22,23}$, to yield fractional plasma volume $\left(v_{\mathrm{p}}\right)$ and other physiological parameters such as the transfer constant $K^{\text {trans }}$. Figure $1 \mathrm{c}$ shows representative $\mathrm{CBF}_{\mathrm{ACcomb}}$ images of a patient with NF2 alongside maps of $v_{\mathrm{p}}$ and $K^{\text {trans }}$
\end{abstract}


derived using the LDHT and FDHS acquisitions of the ICR-DICE ${ }^{14}$. As can be seen from Fig 1c, the LDHT derived $K^{\text {trans }}$ map is free from vessel artifacts, whereas the $K^{\text {trans }}$ map derived from the FDHS showed greater tumor heterogeneity detail thanks to the higher spatial resolution but at the expense of vessel artifacts due to overestimation of $K^{\text {trans }}$ in areas of high $v_{\mathrm{p}}$ resulting from the low temporal resolution $(\Delta \mathrm{t}=10 \mathrm{~s})$.

For direct comparison between various parametric matrices, a data processing pipeline was constructed using SPM scripts ${ }^{16}$ to allow intra-subject spatial alignment between various MR images and derived parametric maps. Segmented tissue masks (WM, GM, $\mathrm{CSF}$, and tumor respectively) were then applied onto parametric maps for generating ROI mean values, or for pixel-by-pixel comparison between multi-parametric maps. For repeated studies, longitudinal spatial alignment was also performed using the ending frame, i.e. the last 3D volume of the LDHT or FDHS DCE series acquired on day 0 as the destiny of the co-registration for all other images of the patient at day0 or day 90 . The comprehensive image spatial alignment between the T2*W-DSC and T1W-DCE images facilitated more convenient visual inspection and pixel-by-pixel comparison of $\mathrm{T} 2 * \mathrm{~W}$ $\mathrm{CBF}$ and $\mathrm{T} 1 \mathrm{~W}-\mathrm{CBF}_{\mathrm{ET}}$ maps.

\section{Statistical Analysis}

The accuracy and precision of the five methods were compared by Monte Carlo simulation of the mean and SD of percent deviations for CBF estimates at varying levels of Rician noise. 
Using the LDHT T1W DCE and T2*W DSC-MRI data from the patient with a GBM, we investigated the concordance in the relationships of $\mathrm{T} 2 * \mathrm{~W}-\mathrm{CBF}$ vs. T2*W-CBV and T1W-CBF $\mathrm{ACcomb}_{\text {vs. }} v_{\mathrm{p}}$ in tumor on a pixel-by-pixel basis. Pixel scatter plots and linear regression analysis were further used to assess concordance of intratumoral $\mathrm{T} 1 \mathrm{~W}-\mathrm{CBF}_{\mathrm{ET}}$ and $\mathrm{T} 2 * \mathrm{~W}-\mathrm{CBF}$ estimates and to assess the intratumoral pixelwise relationship of $\mathrm{T} 2 * \mathrm{~W}$ CBF compared to $\mathrm{T} 2 * \mathrm{~W}-\mathrm{CBV}$, and $\mathrm{T} 1 \mathrm{~W}-\mathrm{CBF}_{\mathrm{ACcomb}}$ compared to $v_{\mathrm{p}}$. Pixelwise concordance between the derived T1W(SVD)-CBF estimates and T1W-CBF ${ }_{\mathrm{ET}}$ and $\mathrm{T} 2 * \mathrm{~W}-\mathrm{CBF}$ data is shown in supplementary data.

In order to assess the reproducibility of the ACcomb method, mean GM and WM CBF values were calculated from each MRI scan, for the 7 sporadic VS patients who underwent two consecutive DCE-MRI acquisitions. The reproducibility of each pairwise comparison was then assessed using the test-retest coefficient of variation $(\mathrm{CoV})$. For each subject, $\mathbf{i}$, the $\mathrm{CoV}$ is the standard deviation, $\boldsymbol{\sigma}_{\mathbf{i}}$, for the two measurements on that subject, divided by the mean, $\boldsymbol{\mu}_{\mathbf{i}}$, for the subject. The overall test-retest CoV for a group of $\mathbf{N}$ subjects is then 24,25

$$
\sqrt{\sum_{i}\left(\sigma_{i} / \mu_{i}\right)^{2} / N}
$$

To compare the pre- and post-treatment values of CBF in patients with NF2, the average CBF values of GM, WM, and tumor (VS) over the whole-volume ROIs were calculated for each visit of each patient, using the five T1W-ET methods respectively. A paired ttest was used to compare the group mean values on day0 and day90. To reduce the potential for Type I errors through multiple comparisons using the five T1W-ET 
methods, the standard significance level of $\mathrm{P}=0.05$ was adjusted using the Bonferroni correction $(\mathrm{C}=5)$ to achieve a family-wise error rate $(\mathrm{FEWR})$ of no more than $5 \%$.

\section{RESULTS}

The VIF and the Tissue Concentration Curves Within the ETW (Hypothesis 1) From the LDHT T1W-DCE MRI Fulfills the Requirements of the Microsphere Model

Figure 2 shows variation in the shape of $C_{\mathrm{b}}(t)$ curves measured from the superior sagittal sinus (SSS) of different individuals, when using the power injector with the same GBCA dose and injection rate. Of the 55 MRI exams studied 92.7\%, had either 5 (43.6\%), 6 $(38.2 \%)$, or $7(10.9 \%)$ data points on the upslope segment prior to the first pass peak of the measured $C_{\mathrm{b}}(t)$ curves.

For a study using the microsphere model, the validity of the technical acquisition needs to be checked by ensuring that the integrated input curve, multiplied by the tissue blood flow, parallels to that of the tissue time-density curve, thus fulfilling one of the requirements of the model ${ }^{1-3}$. Figures $3 \mathrm{a}$ and $3 \mathrm{~b}$ demonstrate an example of this. $\mathrm{INT}_{\text {aif }}$ was calculated by integration of the gamma variant fit of the $C_{\mathrm{b}}(t)$; the measured WM and GM curves were averaged concentration-time curves from the whole-volume ROIs, which were automatically defined from the WM and GM masks respectively. In Fig. 3a, the $\mathrm{INT}_{\text {aif }}$ was time-shifted and scaled to align with the rising bolus time course of the WM concentration curve, resulting in a calculated $f_{\mathrm{wm}}$ of $25 \mathrm{ml} / \mathrm{min} / 100 \mathrm{ml}$. In Fig. $3 \mathrm{~b}$, the 
$\mathrm{INT}_{\text {aif }}$ was time-shifted and scaled to align with the rising bolus time course of the GM concentration curve, resulting in a calculated $f_{\mathrm{gm}}$ of $60 \mathrm{ml} / \mathrm{min} / 100 \mathrm{ml}$.

Figures $3 \mathrm{c}$ and $3 \mathrm{~d}$ show a simulation of the tissue concentration curves based on the microsphere model. The flow-scaled $\mathrm{INT}_{\text {aif }}$ and ROI-averaged WM and GM concentration curves used in the simulation were the same as in Figs. 3a and 3b. The upslope part of the theoretical tissue curve (the working data range, ETW, for CBF measurement) was sampled from the flow-scaled $\mathrm{INT}_{\text {aif, }}$, while keeping the downslope part, starting from and including the tissue peak time point, of the measured tissue curve.

\section{Averaged Concentration Methods Performed Better Than Upslope or Maximum Gradient Methods on Monte Carlo Simulations}

Figure 4 compares percent deviation (mean and $\mathrm{SD}$ ) in $\mathrm{CBF}_{\mathrm{WM}}$ and $\mathrm{CBF}_{\mathrm{GM}}$ derived from ACrMG, ACrPK, ACcomb, upslope, and the traditional MG methods, using various noise levels. The traditional MG method yielded poor accuracy and precision even at small noise levels for simulated WM and GM curves. The upslope method showed better accuracy and precision than the MG method but poorer precision than the averagedconcentration methods, especially at noise levels higher than 3\%. For noise levels higher than $2 \%$, the $\mathrm{CBF}_{\mathrm{WM}}$ estimates obtained from the $\mathrm{ACrMG}$ and the $\mathrm{ACrPK}$ methods behaved oppositely: the ACrMG analysis (green line) overestimates while the $\mathrm{ACrPK}$ (blue line) underestimates $\mathrm{CBF}_{\mathrm{WM}}$. The ACcomb method, which is the average of the $\mathrm{ACrMG}$ and $\mathrm{ACrPK}$ values, estimates $\mathrm{CBF}_{\mathrm{WM}}$ more accurately, and reduces the $\mathrm{SD}$ of 
$\mathrm{PD}$ in $\mathrm{CBF}_{\mathrm{WM}}$ estimation (Figures $4 \mathrm{a}$ and $4 \mathrm{~b}$ ). The $\mathrm{CBF}_{\mathrm{GM}}$ estimates (Figures $4 \mathrm{c}$ and $4 \mathrm{~d}$ ), showed much less variation in the three averaged-concentration methods, which may be due to the more than twofold greater ENR in the GM uptake curves relative to the WM curves for the same noise level. The overall performance of the ACcomb method was better than the other two averaged-concentration methods (ACrMG and ACrPK) at a noise level of $4 \%$ or higher, but consistently underestimated $\mathrm{CBF}_{\mathrm{GM}}$ by about $5 \%$. For noise levels $<4 \%$, the accuracy of $\mathrm{CBF}_{\mathrm{ACrPK}}$ became close to, or better than that of $\mathrm{CBF}_{\mathrm{ACcomb}}$. Furthermore, comparing Fig. $4 \mathrm{a}$ with $4 \mathrm{c}$ revealed that $\mathrm{CBF}_{\mathrm{GM}} / \mathrm{CBF}_{\mathrm{WM}}$ obtained by ACcomb would be on average around 5\% lower than the 'true' $\mathrm{CBF}_{\mathrm{GM}} / \mathrm{CBF}_{\mathrm{WM}}$, while $\mathrm{CBF}_{\mathrm{GM}} / \mathrm{CBF}_{\mathrm{WM}}$ obtained by $\mathrm{ACrPK}$ would be on average $[2 \%$, $5 \%, 11 \%, 14 \%, 15 \%]$ higher than the 'true' $\mathrm{CBF}_{\mathrm{GM}} / \mathrm{CBF}_{\mathrm{WM}}$ with the error increasing with increasing noise level $(0.01,0.02,0.03,0.04,0.05$, respectively). This was because, although $\mathrm{ACrPK}$ underestimated both $\mathrm{CBF}_{\mathrm{GM}}$ and $\mathrm{CBF}_{\mathrm{WM}}$, the size of the negative $\mathrm{PD}$ of $\mathrm{CBF}_{\mathrm{WM}}$ was larger than that of $\mathrm{CBF}_{\mathrm{GM}}$.

\section{Noise Levels For the In Vivo Pixel SI Curves Are Consistent With the Noise Levels Employed In the Simulation}

Figure 5 shows in vivo signal intensity (SI) curves for GM and WM derived from individual voxels (Fig 5a and 5b) and ROIs placed within the GM and WM respectively (see Fig $5 \mathrm{~d}$ and $5 \mathrm{e}$ ), whereas Fig $5 \mathrm{f}$ shows the vascular input function. The SI baseline mean, standard deviation, noise level (= SI baseline SD/mean), ENR and the estimated CBF values are shown on the panel for each of the tissue pixel/ROI SI curves. As can be 
seen, the noise levels for the pixel SI curves acquired from a 1.5T scanner show around $4 \%$ or less, consistent with the noise levels employed in the simulation.

\section{Averaged Concentration Methods Provide More Accurate Estimation of In Vivo CBF Values Than Classical Maximum Gradient (MG)/Upslope Methods}

Figure 6a shows the CBF images derived using the LDHT T1W DCE-MRI (the left five columns) and the T2*W DSC-MRI (the right column) acquired at $3 \mathrm{~T}$ from a patient with a right sided GBM. The left hand panel shows representative axial section taken from the acquired whole brain $3 \mathrm{D} \mathrm{CBF}_{\mathrm{ACcomb}}$ images. Using the $\mathrm{ACcomb}$ method, the calculated mean CBF value was $75.3 \mathrm{ml} / \mathrm{min} / 100 \mathrm{ml}$ for $\mathrm{GM}$ and $32.3 \mathrm{ml} / \mathrm{min} / 100 \mathrm{ml}$ for $\mathrm{WM}$, giving a $\mathrm{CBF}_{\mathrm{GM}} / \mathrm{CBF}_{\mathrm{WM}}$ ratio of 2.33. The derived $\mathrm{CBF}$ maps using the $\mathrm{ACrMG}$ and $\mathrm{ACrPK}$ methods are visually similar to the ACcomb method, but as shown in Figure 6a there is over-estimation of the mean $\mathrm{CBF}$ values of GM and WM when using the classical MG and the upslope methods. The mean ROI CBF values of the GM, WM and tumor derived from the five methods are listed in Table 1 . Spatial alignment of the T2*W DSC-MRI to their T1W counterparts (see Figure 6a), showed expected differences in appearances of the vasculature within both the 'normal' brain and the tumor itself due to the susceptibility effects of intravascular contrast in $\mathrm{T} 2 * \mathrm{~W}$ images. The mean values of the $\mathrm{T} 2 * \mathrm{~W}-\mathrm{CBF}$ and those of $\mathrm{T} 1 \mathrm{~W}-\mathrm{CBF}_{\mathrm{ET}}$ derived by the AC-based methods for both GM and WM are globally compatible, however, as shown in Table 1. 


\title{
Close Intratumoral Pixel-by-Pixel Correlation Between $\mathrm{T} 1 \mathrm{~W}-\mathrm{CBF}_{\mathrm{ACcomb}}$ and Estimates of $v_{p}$ Derived From Extended Tofts Model
}

Figure $6 \mathrm{~b}$ shows the central slice of the $3 \mathrm{D} v_{\mathrm{p}}$ and $\mathrm{T} 2 * \mathrm{~W}-\mathrm{CBV}$ maps from the patient with a GBM. The depicted tumor and brain vasculature on the $v_{\mathrm{p}}$ map are visually very similar to the $\mathrm{T} 1 \mathrm{~W}-\mathrm{CBF}_{\mathrm{AC}} \mathrm{comb}$. This is in concordance with the similarity observed between the $\mathrm{T} 2 * \mathrm{~W}-\mathrm{CBV}$ and $\mathrm{T} 2 * \mathrm{~W}-\mathrm{CBF}$ maps. Figure $6 \mathrm{~b}$ also displays the scatter plots of pixel values of $v_{\mathrm{p}}$ vs T1W-CBF $\mathrm{ACcomb}$ and $\mathrm{T} 2 * \mathrm{~W}-\mathrm{CBV}$ vs $\mathrm{T} 2 * \mathrm{~W}-\mathrm{CBF}$ from the tumor ROI. Visual inspection supported the use of a simple linear regression model, which showed a close correlation between $\mathrm{T} 1 \mathrm{~W}-\mathrm{CBF}_{\mathrm{AC} \text { comb }}$ and $v_{\mathrm{p}}\left(\mathrm{R}^{2}=0.934\right)$. A similar relationship was found between $\mathrm{T} 2 * \mathrm{~W}-\mathrm{CBV}$ and $\mathrm{T} 2 * \mathrm{~W}-\mathrm{CBF}\left(\mathrm{R}^{2}=0.853\right)$. Nevertheless, the scatterplot of tumor voxels of maps of $\mathrm{T} 1 \mathrm{~W}-\mathrm{CBF}_{\mathrm{ACcomb}} \mathrm{Vs} . \mathrm{T} 2 * \mathrm{~W}-\mathrm{CBF}$ and their linear regression displayed a much weaker relationship $\left(\mathrm{R}^{2}=0.263\right)$.

\section{CBF Estimation Using T1W(SVD) Approach Overestimates Tumor CBF}

\author{
As can be seen in Table 1, when using an ROI analysis with parametric maps, T1W \\ (SVD) methods gave mean CBF values for WM and GM compatible with the $\mathrm{T} 2 * \mathrm{~W}$ - \\ SVD and our T1W-CBF-ET method, but overestimated CBF in the tumor itself. Our \\ pixelwise analysis is shown in supplementary data, and showed a close pixelwise \\ correlation between the T1W(SVD) $\mathrm{T} 1 \mathrm{~W}-\mathrm{CBF}_{\mathrm{AC} \text { comb }}$ estimates for both GM and WM.
}




\section{Good Reproducibility of the ACcomb Method Reported In Terms of CoVs}

Table 2 details the test-retest $\mathrm{CoV}$ for $\mathrm{CBF}_{\mathrm{AC} \text { comb }}$ obtained from the seven patients with sporadic VSs. As can be seen the overall test-retest CoV was 5.76 and 8.51 for NAWM and NAGM respectively, showing overall good reproducibility of the $\mathrm{CBF}_{\mathrm{ACcomb}}$ measurements and better reproducibility for NAWM measurements.

\section{Average Concentration ET Methods Show Post-Treatment Increases In Normal Appearing WM CBF In NF2 Patients Treated With Bevacizumab}

Figure 7 shows CBF (top row) maps derived from a NF2 patient with a large left sided vestibular schwannoma and four meningiomas. The $v_{\mathrm{p}}$ images derived using the ETM are also displayed for comparison in the bottom row. Slices from three levels of the 3D parametric images are shown. As can be seen there is some reduction of CBF and $v_{\mathrm{p}}$ within the VS at 90 days and the appearances of the $\mathrm{T} 1 \mathrm{~W}-\mathrm{CBF}_{\mathrm{AC} \text { comb }}$ maps and $v_{\mathrm{p}}$ maps are very similar at each time-point.

Table 3 lists the group mean values ( \pm SD) of CBF for GM, WM, and $\mathrm{CBF}_{\mathrm{GM}} / \mathrm{CBF}_{\mathrm{WM}}$ respectively for the 12 patients with NF2 treated with bevacizumab. Estimated mean values on day0 and day90 using the five different ET methods, are listed. The ACcomb produced mean $\mathrm{CBF}_{\mathrm{GM}}$ of $55.9 \pm 13.9 \mathrm{~mL} / 100 \mathrm{~g} / \mathrm{min}$. $\mathrm{CBF}_{\mathrm{WM}}$ of $25.8 \pm 3.45 \mathrm{~mL} / 100 \mathrm{~g} / \mathrm{min}$ on day $0, \mathrm{CBF}_{\mathrm{GM}}$ of $61.0 \pm 8.28 \mathrm{~mL} / 100 \mathrm{~g} / \mathrm{min}$. 
$\mathrm{CBF}_{\mathrm{WM}}$ of $28.4 \pm 3.43 \mathrm{~mL} / 100 \mathrm{~g} / \mathrm{min}$ on day 90 . The ACcomb and ACrPK methods produced the highest $\mathrm{CBF}_{\mathrm{GM}} / \mathrm{CBF}_{\mathrm{WM}}$ ratios $(2.15-2.34)$, and the least intra-group SD for GM (8.04 - 13.92), and WM (3.06 - 3.45) respectively. With a paired t-test, both the ACbased methods, $\mathrm{ACcomb}$ and $\mathrm{ACrPK}$, show a moderate increase in the group mean value of CBF in NAWM after treatment (Adjusted p values 0.03 and 0.005 respectively). Interestingly, neither the classical MG nor upslope method, show such changes in $\mathrm{WM}$ and GM CBF after treatment.

\section{DISCUSSION}

We present a new method based on the microsphere principle, for estimation of absolute CBF using a low dose high temporal T1W DCE MRI acquisition. This new method allows a more accurate and reliable estimation of absolute CBF, as instead of using a conventional MG-based algorithm, an averaged contrast agent concentration based method is used, which utilizes data points located in a higher ENR segment of the rising bolus time course.

Monte Carlo simulations demonstrated that these AC-based T1W-CBF ${ }_{\mathrm{ET}}$ methods provided more accurate estimates of CBF compared to the MG and slope methods, especially when the ENR is low, such as within normal appearing white matter. The mean $\mathrm{CBF}$ of GM was, however, underestimated when using the $\mathrm{ACrPK}$ and $\mathrm{ACcomb}$ methods. The observed $5 \%$ underestimation in $\mathrm{CBF}_{\mathrm{GM}}$ values using this new combined 
method is, however, in alignment with published simulation results, such as those of $\mathrm{Wu}$ et al. using deconvolution ${ }^{26}$, and those of Kwong et al. using the ET in DSC MRI

In vivo evaluation of this new $\mathrm{T} 1 \mathrm{~W}-\mathrm{CBF}_{\mathrm{ET}}$ algorithm in 20 patients showed that the MG method produced the poorest $\mathrm{CBF}$ estimates $\left(\mathrm{CBF}_{\mathrm{GM}} / \mathrm{CBF}_{\mathrm{WM}}\right.$ ratio less than 1.5$)$ whilst the $\mathrm{ACcomb}$ and $\mathrm{ACrPK}$ methods produced a more reasonable $\mathrm{CBF}_{\mathrm{GM}} / \mathrm{CBF}_{\mathrm{WM}}$ ratio (average $2.15-2.52$ ). The $\mathrm{CBF}_{\mathrm{WM}}$ calculated by $\mathrm{ACrPK}$ was lower than that produced by $\mathrm{ACcomb}$; and the $\mathrm{CBF}_{\mathrm{GM}}$ calculated by $\mathrm{ACrPK}$ was lower than that by $\mathrm{ACcomb}$ for DCE MRI 1.5T data, but higher than that by ACcomb for DCE MRI for 3T data. The $\mathrm{CBF}_{\mathrm{GM}} / \mathrm{CBF}_{\mathrm{WM}}$ ratio produced by $\mathrm{ACrPK}$ (2.52 and 2.30 for $3.0 \mathrm{~T}$ and $1.5 \mathrm{~T}$ data respectively) was higher than that from ACcomb (2.33 and 2.15 for 3.0T and 1.5T data respectively). These in vivo observations were consistent with the Monte Carlo simulations, and can be attributed to the lower ENR on $1.5 \mathrm{~T}$ compared with $3.0 \mathrm{~T}^{13}$.

A correlation between $\mathrm{CBF}$ and $\mathrm{CBV}$ in both normal brain tissue $\mathrm{e}^{21,27}$ and gliomas ${ }^{28}$ has been previously reported using both a simple linear model and the Grubb formula ${ }^{29}$. In our study we compared the relationships between $\mathrm{T} 2 * \mathrm{~W}-\mathrm{CBF}$ and $\mathrm{T} 2 * \mathrm{~W}-\mathrm{CBV}$ and between $\mathrm{T} 1 \mathrm{~W}-\mathrm{CBF}_{\mathrm{ACcomb}}$ and $v_{\mathrm{p}}$ on a pixel-by-pixel basis within a high grade glioma. Both pairs were highly correlated, consistent with previous results ${ }^{28}$. On the other hand, there was a weak pixel wise correlation between the ET derived T1W-CBF and deconvolution derived $\mathrm{T} 2 * \mathrm{~W}-\mathrm{CBF}$ maps. This discrepancy may be due in part to the fundamental differences in mechanism between $\mathrm{T} 1$ relaxivity and $\mathrm{T} 2 *$ susceptibility contrast effects ${ }^{30}$. Alternatively image distortion due to magnetic susceptibility effects, 
especially when using fast $\mathrm{T} 2 * \mathrm{~W}$ - DSC imaging techniques may limit accurate coregistration of T1W-DCE and T2*W-DSC images thereby adversely affecting pixelwise correlations ${ }^{31,32} 33$. Indeed the relatively good concordance between AC based $\mathrm{T} 1 \mathrm{~W}-\mathrm{CBF}_{\mathrm{ET}}$ and deconvolution derived $\mathrm{T} 2 * \mathrm{~W}-\mathrm{CBF}$ values when using a ROI analysis suggests that this may be the case.

In addition to providing more accurate reliable estimates of $\mathrm{CBF}$, the reproducibility of this new AC based method was established by test re-test analysis. The overall coefficient of variation $(\mathrm{CoV})$ for absolute $\mathrm{CBF}$ measured using the ACcomb method compared favourably with a recent study utilising both $\mathrm{H}_{2} \mathrm{O}^{15}$ PET and contrast-enhanced perfusion 34.

Some authors have advocated the use of model free singular value decomposition approaches for CBF derivation from DCE-MRI data. There are, however, distinct advantages to the use of ET methods over SVD approaches. Firstly, T1W(SVD) can not distinguish signal contributions from intra- and extra-vascular space, and is thereby more affected by vessel leakage than the CBF-ET methods. In our study SVD methods applied to $\mathrm{T} 1$ data gave mean $\mathrm{CBF}$ values for $\mathrm{WM}$ and GM comparable to those acquired with T2*W-SVD and T1W-CBF-ET method. However, in tumors, there was overestimation of $\mathrm{CBF}$, an effect we hypothesize is due to BBB breakdown and contrast leakage. In addition, perfusion calculation by deconvolution is critically dependant on the data ENR ${ }^{7}$. In the work by Larsson et al ${ }^{13}$, T1W-DCE MRI data was acquired on a $3 \mathrm{~T}$ scanner with a GBCA dose of $0.05 \mathrm{mmol} / \mathrm{kg}$ to ensure sufficient ENR for pixelwise calculation of CBF 
using Tikhonov's procedure of deconvolution. Despite this, the authors commented that the relatively poor ENR at $1.5 \mathrm{~T}$ prevented the calculation of CBF maps using the deconvolution approach. ${ }^{35}$ Through using data points located in a higher ENR segment of the rising bolus time course, however, our ET methods suffer less from this limitation.

The CBF increases demonstrated using the ACcom and ACrPK method in normal appearing WM (NAWM) at 90 days post bevacizumab treatment were statistically significant, and exceeded our demonstrated reproducibility threshold for WM CBF measurements. This suggests that these changes are genuine rather than due to reproducibility variation, and, whilst this is a preliminary study of only 12 patients, these findings are biologically plausible, as the therapeutic effect of bevacizumab in this group is believed to result from alleviation of intracranial pressure due to reduction in intratumoural oedema ${ }^{36}$. Larger studies will, however, be needed, to further investigate bevacizumab treatment related changes in microcirculatory parameters of normalappearing brain tissues.

The key advantages of our new AC-based T1W-ET methods can be outlined as below:

1) Application of T1W-ET in leaky tissue. The T1W-ET method is less vulnerable to confounding resulting from leakage, re-circulation, and back flux ${ }^{7,11}$.

2) Improved robustness to low signal to noise ratio. Through use of data points located in a higher ENR segment of the rising bolus time course, the AC-based T1W-ET method allows pixel-by-pixel calculation of CBF using T1W-DCE MRI 
acquired at both $1.5 \mathrm{~T}$ and $3 \mathrm{~T}$ scanners, with a GBCA dose as low as 0.02 $\mathrm{mmol} / \mathrm{kg}$.

3) Simplified data processing. When using the AC-based T1W-ET methodology there is no need to measure TOA, de-noise data, or correct for leakage and recirculation.

4) Acquiring 3D DCE-MRI covering the whole brain. A time resolution of $1 \mathrm{~s}$ was chosen in this study, allowing averaging of three GBCA concentration data points when using the new T1W-ET methods, whilst permitting acquisition of 3D DCE images covering the whole brain.

5) No covariance error due to multi-parameter fitting procedure. Calculation of $\mathrm{CBF}$ with $\mathrm{ACcomb}$ does not require multi-parametric fitting, which is prone to covariance errors and 'salt-and-pepper' noise ${ }^{37}$. The generation of $\mathrm{CBF}_{\mathrm{AC} c o m b}$ maps does not require filtering, in contrast to the maps generated using the twocompartment exchange model ${ }^{37}$.

Finally, one important advantage of the new method is that it allows a lower dose of GBCA to be used compared to other methods of determining CBF such as DSC-MRI. To successfully utilize the microsphere model in determining CBF, a low-dose compact contrast bolus injection is optimum to ensure there is no efflux of intravascular tracer before the first pass AIF peak and to enable better determination of the arterial input function peak ${ }^{20}$. Reduced contrast dose is a pertinent clinical concern, as the potential nephrotoxicity of full dose GBCA is well recognized ${ }^{38}$, and there is growing evidence that gadolinium deposition may occur in the brain following repeated exposures ${ }^{39,40}$. 
Patients with CNS tumors, especially more benign lesions, may receive many contrast enhanced MR scans throughout their lifetime. As such, an MR acquisition method, which permits derivation of accurate perfusion metrics using a lower dose of contrast agent, may be of high clinical utility.

There are some limitations in our study. Firstly, the new AC-based methods for CBF measurements were evaluated in only a small cohort of patients with intra-cranial tumors. Secondly, the 3D whole brain acquisition used in the study comes at the expense of lower spatial resolution than methods utilized by other authors, who acquired only 4-10 slices ${ }^{7}$, 21,37. Finally, a uniform value of hematocrit was used in this study, despite expected inhomogeneities in intra- and inter-subject hematocrit. Because measurements of regional cerebral blood flow are dependent upon regional hematocrit, any alteration in this may produce errors in the calculation of regional blood flow.

In conclusion, we have developed and assessed a new early time points (ET) method of estimating absolute CBF using low dose high temporal (LDHT) DCE MRI data. Monte Carlo analysis shows that this new method improves the accuracy of measured absolute $\mathrm{CBF}$ values at different noise levels. In vivo application of this new method showed that the acquired $\mathrm{T} 1-\mathrm{CBF}_{\mathrm{ET}}$ maps displayed excellent gray-white matter flow contrast using a much smaller dose of GBCA than is used for conventional DSC experiments, and the measured values of WM and GM CBF using our new method matched perfusion values in literature. The typical test-retest coefficients of variation observed in this study suggest that T1W-ET measured CBF have sufficient reproducibility to be used in longitudinal 
studies, especially if large changes due to therapeutic intervention are expected, In a cohort of patients with NF2 undergoing treatment with bevacizumab, there was a moderate increase in CBF of normal-appearing white matter 90 days post therapy. Our new method offers advantages over currently used non-invasive methods of $\mathrm{CBF}$ measurement, and may have considerable future utility in clinical perfusion imaging. 


\section{Acknowledgement}

Many thanks to Drs. David Russell and Ibrahim Djoukhadar for the participation of patient recruitment. Many thanks to Dr. Qing Yang, from Apollo Medical System, for helpful discussions. 


\section{Appendix A. Supplementary Data}

Supplementary data to this article can be found online at Dol: 10.17632/hg7vppf6g5.1 


\section{Glossary}

\begin{tabular}{|c|c|c|}
\hline Symbols & Interpretation & unit \\
\hline AIF & Arterial input function & $\mathrm{mmol} / \mathrm{ml}$ \\
\hline $\mathrm{C}_{\mathrm{b}}(t)$ & Blood CA concentration curve & $\mathrm{mmol} / \mathrm{ml}$ \\
\hline $\mathrm{C}_{\mathrm{t}}(t)$ & Tissue CA concentration curve & $\mathrm{mmol} / \mathrm{ml}$ \\
\hline $\mathrm{CBF}$ & Cerebral blood flow & $\mathrm{ml} / \mathrm{min} / 100 \mathrm{ml}$ \\
\hline $\mathrm{rCBF}$ & Relative CBF & None \\
\hline CBV & Cerebral blood volume & $\begin{array}{l}\mathrm{ml} / 100 \mathrm{ml} ; \\
\mathrm{ml} / 100 \mathrm{~g}\end{array}$ \\
\hline$C B F_{E T}$ & $\begin{array}{l}\text { Absolute CBF measured by the Early time (ET) } \\
\text { method }\end{array}$ & $\mathrm{ml} / \mathrm{min} / 100 \mathrm{ml}$ \\
\hline $\mathrm{CBF}_{\mathrm{ACcomb}}$ & $\begin{array}{l}\text { CBF measured using average of the CBF values } \\
\text { obtained from the ACrMG and ACrPK methods. }\end{array}$ & $\mathrm{ml} / \mathrm{min} / 100 \mathrm{ml}$ \\
\hline $\mathrm{CBF}_{\mathrm{ACrMG}}$ & $\begin{array}{l}\text { CBV measured using averaged concentration } \\
\text { referencing the time to maximum gradient }\end{array}$ & $\mathrm{ml} / \mathrm{min} / 100 \mathrm{ml}$ \\
\hline $\mathrm{CBF}_{\text {MGclassical }}$ & $\begin{array}{l}\text { CBF measured using classical Maximum Gradien } \\
\text { method. }\end{array}$ & $\mathrm{ml} / \mathrm{min} / 100 \mathrm{ml}$ \\
\hline $\mathrm{CBF}_{\mathrm{ACrPK}}$ & $\begin{array}{l}\text { CBF measured using averaged concentration } \\
\text { referencing time to peak }\end{array}$ & $\mathrm{ml} / \mathrm{min} / 100 \mathrm{ml}$ \\
\hline $\mathrm{CBF}_{\text {slope }}$ & CBF measured using upslope method & $\mathrm{ml} / \mathrm{min} / 100 \mathrm{ml}$ \\
\hline$\Delta t$ & Update time of DCE or DSC & $\mathrm{S}$ \\
\hline DCE MRI & Dynamic contrast enhancement MRI & \\
\hline
\end{tabular}




\begin{tabular}{|c|c|c|}
\hline DSC MRI & Dynamic susceptibility contrast enhancement MRI & \\
\hline ENR & Enhancement-to-noise ratio & \\
\hline ET & Early time method & \\
\hline ETM & Extended Tofts model & \\
\hline ETW & Early time window & \\
\hline $\begin{array}{l}\text { FDHS DCE } \\
\text { MRI }\end{array}$ & Full dose high spatial resolution DCE MRI & \\
\hline$f_{\mathrm{gm}}$ or $\mathrm{CBF}_{\mathrm{GM}}$ & Blood flow of grey matter & $\mathrm{ml} / \mathrm{min} / 100 \mathrm{ml}$ \\
\hline $\begin{array}{l}f_{\mathrm{wm}} \text { or } \\
\mathrm{CBF}_{\mathrm{WM}}\end{array}$ & Blood flow of white matter & $\mathrm{ml} / \mathrm{min} / 100 \mathrm{ml}$ \\
\hline GBCA & Gadolinium based contrast agent. & \\
\hline GBM & $\begin{array}{l}\text { Glioblastoma Multiforme (syn WHO grade IV } \\
\text { glioma) }\end{array}$ & \\
\hline HCT & Hematocrit. & none $(\%)$ \\
\hline $\mathrm{INT}_{\text {aif }}$ & Integral of AIF & \\
\hline $\begin{array}{l}\text { LDHT DCE- } \\
\text { MRI }\end{array}$ & Low dose high temporal resolution DCE MRI & \\
\hline MG & Maximum Gradient & \\
\hline NAWM & Normal-Appearing WM & \\
\hline PD & $\begin{array}{l}\text { Percentage deviation, } \mathrm{PD}=(\text { measured }- \text { true }) / \text { true } \mathrm{x} \\
100 \%\end{array}$ & \\
\hline PRESTO & (3D) echo-shifted multi-shot echo planar imaging & \\
\hline $\mathrm{R} 1_{\mathrm{N}}$ & Native longitudinal relaxation rate & $\mathrm{s}^{-1}$ \\
\hline
\end{tabular}




\begin{tabular}{|l|l|l|}
\hline ROI & Region of interest & \\
\hline SD & Standard deviation & \\
\hline SSS & Superior sagittal sinus & \\
\hline T1W & Longitudinal relaxation (T1) weighted (MR imaging) & \\
\hline T2*W & Effective transverse relaxation (T2*) weighted & \\
\hline$t_{\text {AIF_peak }}$ & Time to peak of AIF & $\mathrm{s}$ \\
\hline$t_{\mathrm{mg}}$ & Time to maximum gradient & $\mathrm{s}$ \\
\hline TOA & Time of arrival of contrast bolus & $\mathrm{s}$ \\
\hline$t_{\mathrm{peak}}$ & Time to peak & $\mathrm{s}$ \\
\hline$t_{\mathrm{ref}}$ & Reference time point & $\mathrm{s}$ \\
\hline TR/TE & Repetition time and echo time & $\mathrm{ms} / \mathrm{ms}$ \\
\hline VIF & Vascular input function & $\mathrm{mmol} / \mathrm{ml}$ \\
\hline$v_{\mathrm{p}}$ & Plasma volume fraction, $v_{\mathrm{p}}=\mathrm{CBV}(1-\mathrm{HCT})$ & $\mathrm{none}(\%)$ \\
\hline VS & Vestibular Schwannoma & \\
\hline
\end{tabular}




\section{References}

1. Peters AM, Brown J, Hartnell GG, Myers MJ, Haskell C, Lavender JP. Noninvasive measurement of renal blood flow with 99mTc DTPA: comparison with radiolabelled microspheres. Cardiovasc Res 1987;21(11):830-834.

2. Peters AM. Fundamentals of tracer kinetics for radiologists. Br J Radiol 1998;71(851):1116-1129.

3. Koenig M, Klotz E, Luka B, Venderink DJ, Spittler JF, Heuser L. Perfusion CT of the brain: diagnostic approach for early detection of ischemic stroke. Radiology 1998;209(1):85-93.

4. Miles KA, Griffiths MR. Perfusion CT: a worthwhile enhancement? Br J Radiol 2003;76(904):220-231.

5. Nitzl D, Ohlerth S, Mueller-Schwandt F, Angst A, Roos M, Kaser-Hotz B. Dynamic computed tomography to measure tissue perfusion in spontaneous canine tumors. Vet Radiol Ultrasound 2009;50(4):347-352.

6. Moody AR, Martel A, Kenton A, et al. Contrast-reduced imaging of tissue concentration and arterial level (CRITICAL) for assessment of cerebral hemodynamics in acute stroke by magnetic resonance. Invest Radiol 2000;35(7):401-411.

7. Kwong KK, Reese TG, Nelissen K, et al. Early time points perfusion imaging. Neuroimage 2011;54(2):1070-1082.

8. Buxton RB. Quantifying CBF with arterial spin labeling. J Magn Reson Imaging 2005;22(6):723-726. 
9. Kimura T, Kusahara H. Reference-based maximum upslope: a CBF quantification method without using arterial input function in dynamic susceptibility contrast MRI. Magn Reson Med Sci 2009;8(3):107-120.

10. Miles KA. Perfusion CT for the assessment of tumour vascularity: which protocol? Br J Radiol 2003;76 Spec No 1:S36-42.

11. Kwong KK, Chesler DA. Early time points perfusion imaging: theoretical analysis of correction factors for relative cerebral blood flow estimation given local arterial input function. Neuroimage 2011;57(1):182-189.

12. Kwong KK, Wu O, Chan ST, Nelissen K, Kholodov M, Chesler DA. Early time points perfusion imaging: relative time of arrival, maximum derivatives and fractional derivatives. Neuroimage 2011;57(3):979-990.

13. Larsson HB, Hansen AE, Berg HK, Rostrup E, Haraldseth O. Dynamic contrastenhanced quantitative perfusion measurement of the brain using T1-weighted MRI at 3T. J Magn Reson Imaging 2008;27(4):754-762.

14. Li KL, Buonaccorsi G, Thompson G, et al. An improved coverage and spatial resolution--using dual injection dynamic contrast-enhanced (ICE-DICE) MRI: a novel dynamic contrast-enhanced technique for cerebral tumors. Magn Reson Med 2012;68(2):452-462.

15. Moonen C, Liu G, Van Gelderen P, Sobering G. A fast gradient-recalled MRI technique with increased sensitivity to dynamic susceptibility effects. Mag Res Med 1992;26:184-189.

16. Ashburner J, Friston K. Multimodal image coregistration and partitioning--a unified framework. Neuroimage 1997;6(3):209-217. 
17. Konig M. Brain perfusion CT in acute stroke: current status. Eur J Radiol 2003;45 Suppl 1:S11-22.

18. Li KL, Zhu X, Zhao S, Jackson A. Blood-brain barrier permeability of normalappearing white matter in patients with vestibular schwannoma: A new hybrid approach for analysis of T1 -W DCE-MRI. J Magn Reson Imaging 2017;46(1):79-93.

19. Zhu XP, Li KL, Kamaly-Asl ID, et al. Quantification of endothelial permeability, leakage space, and blood volume in brain tumors using combined T1 and T2* contrast-enhanced dynamic MR imaging. J Magn Reson Imaging 2000;11(6):575585.

20. Ostergaard L. Principles of cerebral perfusion imaging by bolus tracking. J Magn Reson Imaging 2005;22(6):710-717.

21. Larsson HB, Courivaud F, Rostrup E, Hansen AE. Measurement of brain perfusion, blood volume, and blood-brain barrier permeability, using dynamic contrast-enhanced T(1)-weighted MRI at 3 tesla. Magn Reson Med 2009;62(5):1270-1281.

22. Tofts PS. Modeling tracer kinetics in dynamic Gd-DTPA MR imaging. J Magn Reson Imaging 1997;7(1):91-101.

23. Fritz-Hansen T, Rostrup E, Sondergaard L, Ring PB, Amtorp O, Larsson HB. Capillary transfer constant of Gd-DTPA in the myocardium at rest and during vasodilation assessed by MRI. Magn Reson Med 1998;40(6):922-929. 
24. Jahng GH, Song E, Zhu XP, Matson GB, Weiner MW, Schuff N. Human brain: reliability and reproducibility of pulsed arterial spin-labeling perfusion MR imaging. Radiology 2005;234(3):909-916.

25. Waterton JC, Solloway S, Foster JE, et al. Diurnal variation in the femoral articular cartilage of the knee in young adult humans. Magn Reson Med 2000;43(1):126-132.

26. Wu O, Ostergaard L, Koroshetz WJ, et al. Effects of tracer arrival time on flow estimates in MR perfusion-weighted imaging. Magn Reson Med 2003;50(4):856864.

27. Rostrup E, Knudsen GM, Law I, Holm S, Larsson HB, Paulson OB. The relationship between cerebral blood flow and volume in humans. Neuroimage 2005;24(1):1-11.

28. Shin JH, Lee HK, Kwun BD, et al. Using relative cerebral blood flow and volume to evaluate the histopathologic grade of cerebral gliomas: preliminary results. AJR Am J Roentgenol 2002;179(3):783-789.

29. Grubb RL, Jr., Raichle ME, Eichling JO, Ter-Pogossian MM. The effects of changes in $\mathrm{PaCO} 2$ on cerebral blood volume, blood flow, and vascular mean transit time. Stroke 1974;5(5):630-639.

30. Bruening R, Kwong KK, Vevea MJ, et al. Echo-planar MR determination of relative cerebral blood volume in human brain tumors: $\mathrm{T} 1$ versus $\mathrm{T} 2$ weighting. AJNR AmJNeuroradiol 1996;17(5):831-840. 
31. Bleeker EJ, van Buchem MA, van Osch MJ. Optimal location for arterial input function measurements near the middle cerebral artery in first-pass perfusion MRI. J Cereb Blood Flow Metab 2009;29(4):840-852.

32. Haroon HA, Patankar TF, Zhu XP, et al. Comparison of cerebral blood volume maps generated from $\mathrm{T} 2 *$ and $\mathrm{T} 1$ weighted MRI data in intra-axial cerebral tumours. Br J Radiol 2007;80(951):161-168.

33. Alcaide-Leon P, Pareto D, Martinez-Saez E, Auger C, Bharatha A, Rovira A. Pixel-by-Pixel Comparison of Volume Transfer Constant and Estimates of Cerebral Blood Volume from Dynamic Contrast-Enhanced and Dynamic Susceptibility Contrast-Enhanced MR Imaging in High-Grade Gliomas. AJNR Am J Neuroradiol 2015;36(5):871-876.

34. Carroll TJ, Teneggi V, Jobin M, et al. Absolute quantification of cerebral blood flow with magnetic resonance, reproducibility of the method, and comparison with H2(15)O positron emission tomography. J Cereb Blood Flow Metab 2002;22(9):1149-1156.

35. Larsson HB, Rosenbaum S, Fritz-Hansen T. Quantification of the effect of water exchange in dynamic contrast MRI perfusion measurements in the brain and heart. Magn ResonMed 2001;46(2):272-281.

36. Li K, Djoukhadar I, Zhu X, et al. Vascular biomarkers derived from dynamic contrast-enhanced MRI predict response of vestibular schwannoma to antiangiogenic therapy in type 2 neurofibromatosis. Neuro Oncol 2015. 
37. Sourbron S, Ingrisch M, Siefert A, Reiser M, Herrmann K. Quantification of cerebral blood flow, cerebral blood volume, and blood-brain-barrier leakage with DCE-MRI. Magn Reson Med 2009;62(1):205-217.

38. McDonald RJ, McDonald JS, Newhouse JH, Davenport MS. Controversies in Contrast Material-induced Acute Kidney Injury: Closing in on the Truth? Radiology 2015;277(3):627-632.

39. Kanal E, Tweedle MF. Residual or retained gadolinium: practical implications for radiologists and our patients. Radiology 2015;275(3):630-634.

40. McDonald RJ, McDonald JS, Kallmes DF, et al. Gadolinium Deposition in Human Brain Tissues after Contrast-enhanced MR Imaging in Adult Patients without Intracranial Abnormalities. Radiology 2017:161595. 


\section{Table 1.}

ROI mean values of CBF measured from the patient with GBM using different CBF calculation methods. MRI data were acquired on a 3.0T scanner.

\begin{tabular}{|c|c|c|c|c|c|}
\hline acquisition & analysis method & $\begin{array}{c}\mathrm{CBF}_{\mathrm{GM}} \\
(\mathrm{ml} / \mathrm{min} / 100 \mathrm{ml})\end{array}$ & $\begin{array}{c}\mathrm{CBF}_{\mathrm{WM}} \\
(\mathrm{ml} / \mathrm{min} / 100 \mathrm{ml})\end{array}$ & $\mathrm{CBF}_{\mathrm{GM}} / \mathrm{CBF}_{\mathrm{WM}}$ & $\begin{array}{c}\mathrm{CBF} \text { of tumor } \\
(\mathrm{ml} / \mathrm{min} / 100 \mathrm{ml})\end{array}$ \\
\hline T1W-DCE & $\mathrm{ACcomb}$ & $75.3 \pm 64.6$ & $32.3 \pm 22.8$ & 2.33 & $96.0 \pm 52.9$ \\
\hline & ACrMG & $72.5 \pm 56.7$ & $33.5 \pm 21.9$ & 2.16 & $88.4 \pm 48.5$ \\
\hline & ACrPK & $78.2 \pm 66.2$ & $31.1 \pm 24.9$ & 2.52 & $103.7 \pm 39.5$ \\
\hline & classicalMG. & $180.1 \pm 64.6$ & $128.9 \pm 22.8$ & 1.39 & $194.4 \pm 52.9$ \\
\hline & upslope & $110.3 \pm 83.4$ & $47.7 \pm 36.6$ & 2.31 & $129.7 \pm 79.2$ \\
\hline T2*W-DSC & SVD & $71.5 \pm 66.6$ & $36.7 \pm 26.9$ & 1.95 & $111.0 \pm 75.6$ \\
\hline T1W-DCE & SVD & $76.3 \pm 78.5$ & $37.5 \pm 27.1$ & 2.01 & $130.7 \pm 69.8$ \\
\hline
\end{tabular}


Table 2.

Reproducibility (CoV) of absolute CBF measured in NAWM and NAGM with the ACcomb method. Mean CBF values were calculated using ROIs at 1.5 T scanner.

\begin{tabular}{|c|c|c|c|c|c|c|c|c|}
\hline \multicolumn{2}{|c|}{ Patient with sporadic VS } & \multicolumn{3}{c|}{ NAWM } & \multicolumn{3}{c|}{ NAGM } \\
\hline No. & Age (y) & Sex & Visit 1 & Visit 2 & CoV & Visit 1 & Visit 2 & CoV \\
\hline 1 & 67 & M & 31.97 & 31.18 & 1.78 & 77.09 & 72.80 & 4.06 \\
\hline 2 & 77 & M & 16.43 & 15.63 & 3.57 & 39.30 & 32.42 & 13.56 \\
\hline 3 & 54 & M & 28.08 & 25.80 & 5.97 & 60.52 & 60.10 & 0.49 \\
\hline 4 & 69 & M & 25.31 & 25.31 & 0.01 & 51.35 & 55.37 & 5.33 \\
\hline 5 & 67 & M & 22.99 & 24.52 & 4.58 & 49.45 & 51.60 & 3.02 \\
\hline 6 & 37 & M & 26.32 & 31.35 & 12.33 & 47.01 & 56.00 & 12.34 \\
\hline 7 & 65 & M & 23.14 & 24.05 & 2.74 & 42.80 & 49.86 & 10.78 \\
\hline \multicolumn{2}{|c|}{ Mean CoV \pm SD } & & $4.43 \pm 3.98$ & & & $7.08 \pm 5.09$ \\
\hline
\end{tabular}


Table 3.

Comparison of group mean CBF ( $\mathrm{ml} / \mathrm{min} / 100 \mathrm{ml})$ between day0 and day90 in GM, WM, and $\mathrm{CBF}_{\mathrm{GM}} / \mathrm{CBF}_{\mathrm{WM}}$ in 12 patients with $\mathrm{NF} 2$, estimated using different methods. MRI data were acquired on a $1.5 \mathrm{~T}$ scanner. $P$-values from paired two-tailed t-tests $(\mathrm{df}=11)$ were listed for each paired data.

\begin{tabular}{|c|c|c|c|c|c|c|c|c|c|c|}
\hline \multirow[b]{2}{*}{ methods } & \multirow{2}{*}{$\begin{array}{l}\text { tissue } \\
\text { CBF }\end{array}$} & \multicolumn{3}{|c|}{$\mathrm{CBF}_{\mathrm{GM}}$} & \multicolumn{3}{|c|}{$\mathrm{CBF}_{\mathrm{WM}}$} & \multicolumn{3}{|c|}{$\mathrm{CBF}_{\mathrm{GM}} / \mathrm{CBF}_{\mathrm{WM}}$} \\
\hline & & day0 & day90 & $P$-value & day0 & day90 & $P$-value & day0 & day90 & $P$-value \\
\hline ACcomb & $\begin{array}{l}\text { mean } \\
\pm \mathrm{SD}\end{array}$ & $\begin{array}{r}55.90 \\
\pm 13.92\end{array}$ & $\begin{array}{r}61.00 \\
\pm 8.28\end{array}$ & 0.093 & $\begin{array}{l}25.83 \\
\pm 3.45\end{array}$ & $\begin{array}{r}28.43 \\
\pm 3.42\end{array}$ & $0.006 *$ & $\begin{array}{r}2.15 \\
\pm 0.28\end{array}$ & $\begin{array}{r}2.15 \\
\pm 0.18\end{array}$ & 0.978 \\
\hline ACrMG & $\begin{array}{l}\text { mean } \\
\pm \mathrm{SD}\end{array}$ & $\begin{array}{r}60.85 \\
\pm 17.13\end{array}$ & $\begin{array}{r}67.11 \\
\pm 9.37\end{array}$ & 0.122 & $\begin{array}{r}29.99 \\
\pm 4.36\end{array}$ & $\begin{array}{r}32.97 \\
\pm 4.13\end{array}$ & 0.017 & $\begin{aligned} & 2.01 \\
\pm & 0.31\end{aligned}$ & $\begin{array}{r}2.04 \\
\pm 0.17\end{array}$ & 0.667 \\
\hline $\mathrm{ACrPK}$ & $\begin{array}{l}\text { mean } \\
\pm \mathrm{SD}\end{array}$ & $\begin{array}{r}50.94 \\
\pm 11.51\end{array}$ & $\begin{array}{r}54.88 \\
\pm 8.04\end{array}$ & 0.094 & $\begin{array}{l}21.67 \\
\pm 3.06\end{array}$ & $\begin{array}{r}23.90 \\
\pm 3.17\end{array}$ & $0.001 *$ & $\begin{array}{r}2.34 \\
\pm 0.28\end{array}$ & $\begin{array}{r}2.30 \\
\pm 0.24\end{array}$ & 0.567 \\
\hline classicalMG & $\begin{array}{l}\text { mean } \\
\pm \mathrm{SD}\end{array}$ & $\begin{array}{r}155.56 \\
\pm 17.15\end{array}$ & $\begin{array}{r}159.50 \\
\pm 35.58\end{array}$ & 0.726 & $\begin{array}{r}128.35 \\
\pm 29.06\end{array}$ & $\begin{array}{r}124.08 \\
\pm 35.23\end{array}$ & 0.721 & $\begin{aligned} & 1.25 \\
\pm & 0.20\end{aligned}$ & $\begin{array}{r}1.32 \\
\pm 0.19\end{array}$ & 0.198 \\
\hline upslope & $\begin{array}{l}\text { mean } \\
\pm \mathrm{SD}\end{array}$ & $\begin{array}{r}75.42 \\
\pm 16.60\end{array}$ & $\begin{array}{r}81.33 \\
\pm 16.56\end{array}$ & 0.123 & $\begin{array}{r}36.59 \\
\pm 4.45\end{array}$ & $\begin{array}{r}39.48 \\
\pm 6.18\end{array}$ & 0.136 & $\begin{array}{c}2.07 \\
\pm 0.38\end{array}$ & $\begin{array}{r}2.06 \\
\pm 0.24\end{array}$ & 0.912 \\
\hline
\end{tabular}

* Significant at $P<0.01$ (with Bonferroni correction) 


\section{Figure Legends}

\section{Figure 1:}

Figure 1a shows a diagram of 3D fast field echo (FFE) pulse sequence with $\mathrm{TR} / \mathrm{TE} / \alpha=$ $2.95 \mathrm{~ms} / 0.66 \mathrm{~ms} /\left[2^{\circ}, 8^{\circ}, 15^{\circ}, 20^{\circ}\right]$, used for the LDHT-DCE-MRI. This short TR gradient recalled echo based pulse sequence is embedded with both gradient spoiler and phase cycling for the elimination of the net transverse magnetization. The gradient spoilers are applied along read and slab selection directions. The phase cycling has a phase increment angle of $117^{\circ}$. The $3 \mathrm{D}$ data block covers whole brain without use of a RF prepulse, such as the regional saturation technique (REST) by Philips to achieve minimum TR and maximum temporal resolution.

Figure 1b shows the last frame of a 3D FDHS-DCE $(T=600 \mathrm{~s})$ acquisition (left column), in a patient with neurofibromatosis type 2 with a large right sided vestibular schwannoma (see overlaid tumor mask) and multiple meningiomas. The middle and right columns show the last frame of 3D LDHT-DCE $(T=300 \mathrm{~s})$ overlaid with the segmented grey matter mask or segmented WM mask respectively.

Figure 1c shows maps of $\mathrm{CBF}_{\mathrm{ACcomb}}$ (top left panel, in $\mathrm{ml} / \mathrm{min} / 100 \mathrm{ml}$ ) and $v_{\mathrm{p}}$ derived from ETM (bottom left panel) in the same patient as shown in Fig 1b. The right column shows maps of $K^{\text {trans }}\left(\mathrm{min}^{-1}\right)$ from LDHT MRI (top) or FDHS MRI (bottom), both derived from the ETM. The LDHT derived $K^{\text {trans }}$ map is free from vessel artifacts, whereas the $K^{\text {trans }}$ map derived from the FDHS showed greater tumor heterogeneity detail thanks to 
the higher spatial resolution but at the expense of vessel artifacts due to the low temporal resolution $(\Delta \mathrm{t}=10 \mathrm{~s})$.

Figure 2. a. Distribution of number of exams with various number of data points on the upslope segment prior to the first pass peak of the measured $C_{\mathrm{b}}(t)$ curves. The bottom row shows the typical $C_{\mathrm{b}}(t)$ curves with upslope data points of 4 (b. acquired from a 16-year old male of $85 \mathrm{~kg}$ body weight), 6 (c. acquired from a 16-year old female of $60 \mathrm{~kg}$ body weight), and 8 (d. acquired from a 25-year old male of $107 \mathrm{~kg}$ body weight).

Figure 3. Assessment of validity of LDHT-T1W DCE MRI for microsphere CBF analysis ( $\mathrm{a}$ and $\mathrm{b}$ ), and simulation of the 'theoretical' WM and GM curves for Monte Carlo error analysis (c and d). Fig. 3a shows the integrated input curve, multiplied by $f_{w m}$ $=25 \mathrm{ml} / \mathrm{min} / 100 \mathrm{ml}=0.00417 \mathrm{ml} / \mathrm{s} / \mathrm{ml}$, and time-shifted to align with the rising bolus time course of the WM concentration curve. Fig. $3 \mathrm{~b}$ shows the integrated input curve, multiplied by $\mathrm{f}_{\mathrm{gm}}=60 \mathrm{ml} / \mathrm{min} / 100 \mathrm{ml}=0.01 \mathrm{ml} / \mathrm{s} / \mathrm{ml}$, and time-shifted to align with the rising bolus time course of the GM concentration curve. Figures $3 c$ and $3 d$ showed the simulated WM and GM concentration curves respectively.

Figure 4. PD analysis for absolute CBF estimates using different methods. Mean (4a and 4c) and SD (4b and 4d) of percent deviations for CBF of WM (4a and 4b) and CBF of GM (4c and 4d) calculated from 20,000 Monte Carlo repetitions of fitting individual SItime curves using the ACrMG (green), ACrPK (blue), ACcomb (red), upslope (black) and the traditional MG (purple) methods. 
Figure 5. SI curves for representative voxels in GM and WM and for a ROI of a relevant size together with the vascular input function: a) a pixel GM SI-time curve; b) a pixel WM SI-time curve; c) GM (filled square) and WM (circle) ROIs; d) mean SI curve from the GM ROI; e) mean SI curve from the WM ROI; f) vascular input function measured from the superior sagittal sinus. The dashed line in each plot indicates the estimated time of bolus arrival for global AIF.

Figure 6. Figure 6a shows visual comparison of $\mathrm{CBF}$ images obtained from a patient with a glioblastoma multiforme on a $3 \mathrm{~T}$ scanner. The left five columns show CBF images from the LDHT T1W DCE MRI calculated with the five ET methods. The right column shows CBF from T2*W DSC MRI calculated with a deconvolution method.

Figure $6 \mathrm{~b}$ shows the $v_{\mathrm{p}}$ map derived from ETM (left panel), and the T2*W-CBV map (right panel) from the same patient. The 2 nd panel from left shows the intratumoral pixelby-pixel comparison of $v_{\mathrm{p}}$ and $\mathrm{CBF}_{\mathrm{ACcomb}}$, both obtained from the LDHT T1W-DCE MRI, while the $2^{\text {nd }}$ panel from right shows the intratumoral pixel-by-pixel comparison of CBV and CBF derived by SVD-deconvolution, both from the T2*W-DSC MRI.

Figure 7. $\mathrm{T} 1 \mathrm{~W}-\mathrm{CBF}_{\mathrm{ACcomb}}$ (top row) and $v_{\mathrm{p}}$ maps (bottom row) derived using the extended Tofts model in an NF2 patient with a large left sided vestibular schwannoma and multiple meningiomas. These maps were derived from the low dose T1W DCE-MRI acquired on a $1.5 \mathrm{~T}$ scanner, pre- and 90 days post- bevacizumab therapy. Slices from three levels of the 3D maps of $\mathrm{CBF}$ and $v_{\mathrm{p}}$ are displayed, which show: a vestibular 
schwannoma within the left cerebellopontine angle (left two columns, white arrow); a representative slice at the level of the centrum semiovale (middle two columns); and a right sided occipitoparietal meningioma (right two columns, white arrow). 


\section{Low Dose T1W DCE-MRI for Early Time Points (ET) Perfusion Measurement in Patients with Intra-Cranial Tumors: A Pilot Study Applying the Microsphere Model to Measure Absolute Cerebral Blood Flow}

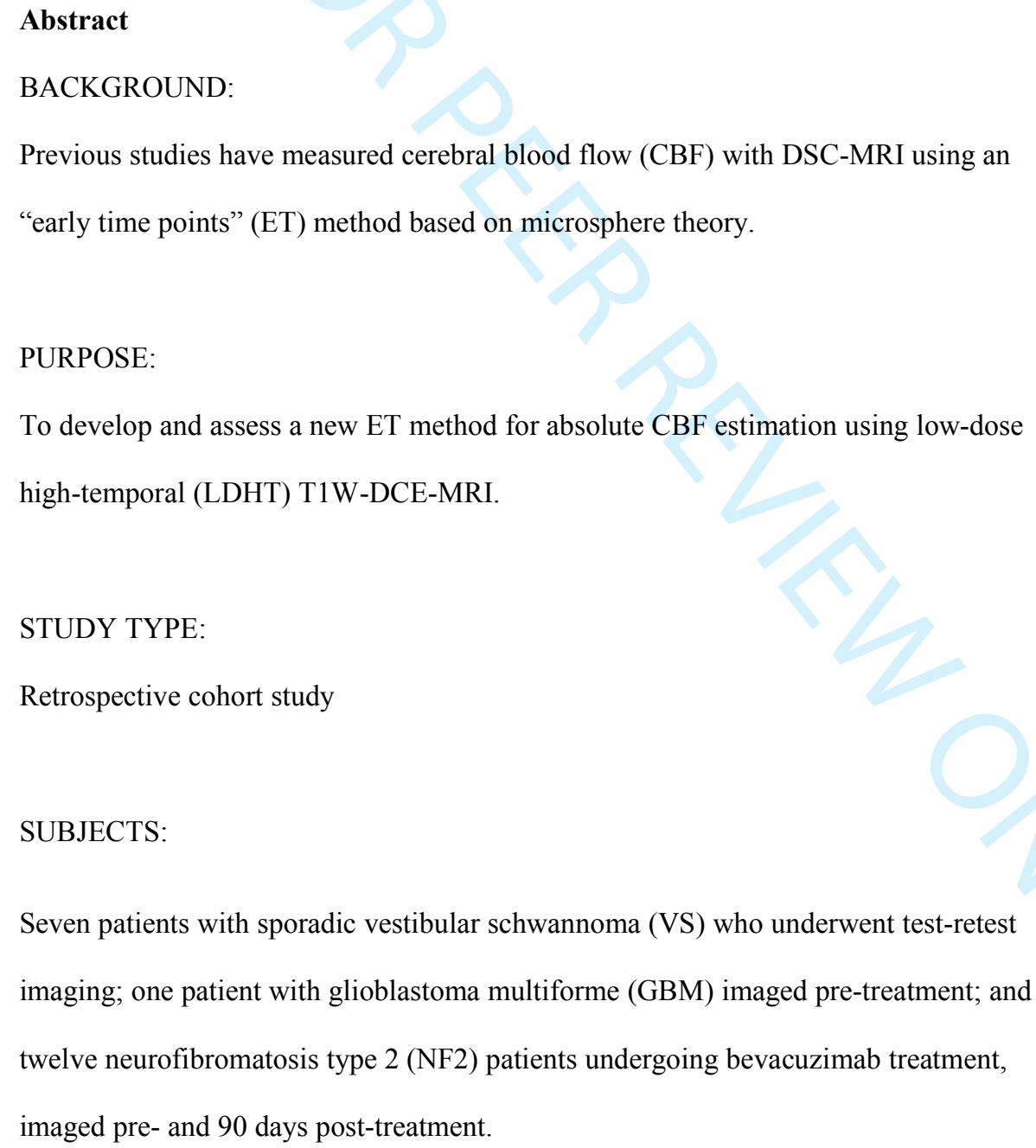




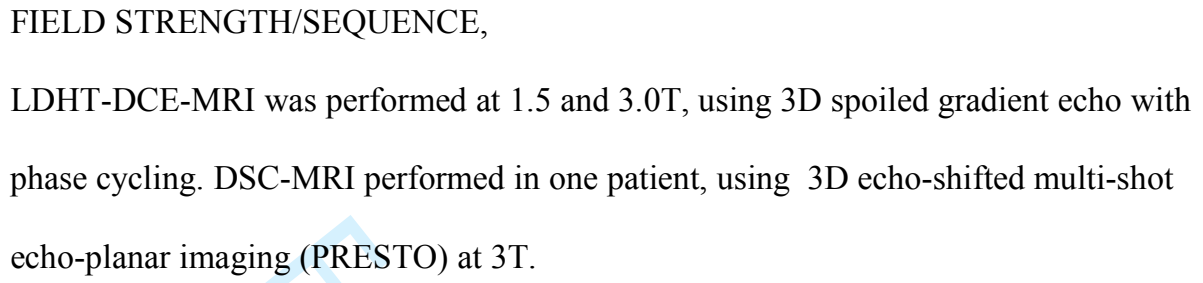

\section{ASSESSMENT:}

Through Monte Carlo simulations, CBF estimation using three newly developed average contrast agent concentration (AC) based methods (ACrPK, ACrMG, ACcomb), was compared against conventional maximum gradient (MG) approaches, at varying Rician noise levels. Reproducibility and applicability of the ACcomb method was assessed in our sporadic-VS/GBM/NF2 patient cohort respectively.

\section{STATISTICAL TESTS:}

Reproducibility was measured using test-retest coefficient of variation $(\mathrm{CoV})$. Pre- and post-treatment $\mathrm{CBF}$ values were compared using paired t-test with Bonferroni correction.

\section{RESULTS:}

Monte Carlo stimulations demonstrated that AC-based methods, particularly ACcomb, offered superior accuracy to conventional MG approaches. Overall test-retest CoV using the ACcomb method was 5.76 in normal-appearing white matter (NAWM). The new ACcomb method produced GM/WM CBF estimates in the NF2 patient cohort of $55.9 \pm 13.9 / 25.8 \pm 3.5$ on day 0 ; compared to $155.6 \pm 17.2 / 128.4 \pm 29.1$ for the classical MG method. There was a moderate (10\% using ACcomb and ACrpk) increase in CBF of 
NAWM 90 days post therapy $(\mathrm{P}=0.03$ and 0.005$)$.

\section{DATA CONCLUSION:}

Our new AC based method of CBF estimation offers excellent reproducibility, and displays more accuracy in both Monte Carlo analysis and clinical data application, than conventional MG based approaches.

Keywords: Low dose gadolinium based contrast agent, cerebral blood flow, dynamic susceptibility contrast-enhanced MRI, dynamic contrast enhanced MRI, early time points, intra-cranial tumor 


\section{INTRODUCTION}

The microsphere method is a classic technique for blood flow quantification, based on the principle that injected labelled particles, which are too big to fit through the capillaries, are delivered to each tissue element in proportion to the local blood flow, and remain trapped there for subsequent counting. While the classical microsphere method is restricted to animal studies, the microsphere model ${ }^{1-3}$ has become the basis for blood flow quantification in both computed tomography $(\mathrm{CT})^{\frac{3-5}{3}}$, and perfusion MRI $\frac{6-9}{\text {. }}$.

The maximum gradient (MG) method for calculation of cerebral blood flow (CBF) is based on the microsphere model and has been widely applied in perfusion $\mathrm{CT}^{3,10}$. Recently, Kwong et al $\frac{7,11,12}{}$ proposed a technique utilizing the early data points of the contrast agent $(\mathrm{CA})$ bolus for relative $\mathrm{CBF}(\mathrm{rCBF})$ calculation with dynamic susceptibility contrast (DSC) MRI. They used measurement from early time points before the gadolinium based contrast agent (GBCA) has left the tissue, i.e. the time window which meets the microsphere prerequisite. They named the region of the time course curve that meets the requirements of the microsphere model the "early time points window (ETW)" and the analysis technique the "early time points" (ET) method. They proposed that as long as the microsphere prerequisite is satisfied, different ways of manipulating the early rising bolus concentration time course would theoretically yield the same $\mathrm{rCBF}$ result, but that one method could prove superior to another under specific noise conditions, and that measurement of absolute blood flow could be achieved with sampling of arterial blood from appropriate arteries $\frac{7,11,12}{\text {. }}$ 
The MG method has however, not been broadly accepted in T1 weighted (T1W) dynamic contrast enhanced (DCE) MRI evaluation of $\mathrm{CBF}^{13}$. There are two main reasons for this: Firstly, the use of the MG method in DCE-MRI data requires that the microsphere prerequisite is met $^{7}$ which depends on various factors, including: contrast bolus volume, injection rate and the patient's cardiac output ${ }^{10}$. Secondly ${ }_{2} ;$ the MG method requires good enhancement-to-noise ratio (ENR, maximal signal change divided by the standard deviation of the baseline of the DCE-MRI), which may not always be met in early timepoint DCE MRI images used to calculate perfusion. The aim of the current study was to therefore develop and assess a new methodology for absolute CBF estimation which uses data derived from a low dose whole brain 3D coverage T1W DCE MRI acquisition, and is based on the microsphere and ET strategies.

\section{MATERIALS AND METHODS}

\section{Patients}

We retrospectively analyzed MRI data from twenty patients, which had been prospectively collected for a previous study using the same T1W DCE MRI protocol. Twelve patients with type 2 neurofibromatosis (NF2), seven patients with sporadic vestibular schwannomas (VS), and one patient with histologically proven glioblastoma multiforme (GBM) were recruited into the study. Ethical approval was in place for the

study (-NHS Health Research Authority; NRES committee North West 13/NW/0131) and all participants had previously consented for later data analysis of their MRI data. Amongst the twelve NF2 patient cohort there were 21 vestibular schwannomas and 11 
meningiomas. All twelve patients with NF2 were undergoing treatment with the antiVascular Endothelial Growth Factor antibody, bevacizumab, and underwent imaging on two occasions: pre-treatment (day0) and 3 months (day90) following treatment. The seven patients with sporadic VS cohort were imaged on two separate occasions 4 days apart.

MRI

The 12 Patients with NF2 and seven patients with sporadic VS were imaged on a $1.5 \mathrm{~T}$ scanner (Philips Achieva, Best, Netherlands) using an 8-channel head coil. The patient with a GBM was imaged on a 3.0T scanner (Philips Achieva, 3.0TX).

The following scanning protocols were employed: 1) Higher spatial resolution morphological MRI, e.g. high spatial resolution non-enhanced (C-) 3D T1-weighted (T1W) MRI to support tissue segmentation, and contrast enhanced (C+) T1W gradient echo for extracting tumor enhanced volume. 2) DCE-MRI. Low GBCA dose, high temporal resolution (LDHT) DCE-MRI data were collected as the first part of the dual temporal resolution technique, an improved coverage and spatial resolution-using Dual Injection dynamic Contrast-Enhanced (ICR-DICE), as described previously ${ }^{14}$. Variable flip angle $\left(\alpha=2^{\circ}, 8^{\circ}, 15^{\circ}\right.$ and $\left.20^{\circ}\right)$ acquisitions were performed prior to the LDHT-DCE series for native longitudinal relaxation rate $\left(\mathrm{R} 1_{\mathrm{N}}\right)$ mapping. The LDHT-DCE MRI uses the same 3D GRE sequence with a flip angle of $20^{\circ}$, with an FOV of $240 \times 240 \mathrm{~mm}$, image matrix of $96 \times 96 \times 22$ voxels, sense acceleration factor of 1.8, and temporal 
resolution of $\Delta t=1.0 \mathrm{~s}(\mathrm{n}=300)$ (Fig. 1a). A low dose (fixed volume of $3 \mathrm{ml}, 0.02$ $\mathrm{mmol} / \mathrm{kg}$ depending on body weight) of macrocyclic GBCA (gadoterate meglumine; Dotarem, Geurbet, Roissy, France) was administered by power injector as an intravenous bolus at a rate of $3 \mathrm{ml} / \mathrm{s}$, followed by a chaser of $20 \mathrm{mls}$ of $0.9 \%$ saline administered at the same rate. This LDHT acquisition was then followed by a full GBCA dose $(0.1$ $\mathrm{mmol} / \mathrm{kg}$ ), high-spatial resolution (matrix size of $240 \times 240 \times 70$ ) acquisition (FDHS) DCE MRI. As the name of ICR-DICE indicates, a large acquisition volume covering the whole brain is used in order to eliminate unsaturated flowing spins enter the imaging slab, which can cause undesirable signal enhancement and generate image artifacts. To obtain satisfactory elimination of in-flow artifacts, it is paramount important that (1) the volume coverage of 3D slab is large enough to incorporate the top of the brain, the circle of Willis and the terminations of the internal carotid arteries bilaterally (Fig 1b); (2) The read gradient of the $3 \mathrm{D}$ slab is orientated in parallel to the vessels for the maximum saturation of the out slab upstream. 3) For the GBM patient, following the T1W-DCE MRI acquisition, a dynamic susceptibility contrast enhancement imaging (DSC) series was undertaken, using a 3D echo-shifted multi-shot echo-planar imaging (3D PRESTO) $)^{15}$. The PRESTO series used scan parameters of TR/TE/flip angle of $20 \mathrm{~ms} / 26.5 \mathrm{~ms} / 10^{\circ}$. The contrast bolus administered for the T1W-DCE MRI acquisitions was used as the preload for leakage correction, and a third injection of $0.1 \mathrm{mmol} / \mathrm{kg}$ of Dotarem followed by a saline flush was administered at the 5th dynamic frame of the 3D PRESTO-DSC. The DSC has an image matrix of $128 \times 128 \times 30$ and $\Delta t$ of $1.5 \mathrm{~s}$.

\section{Image Co-registration and Segmentation}


$\mathrm{SPM}^{16}$ was used for image co-registration and segmentation of the MRI data into GM, WM, and CSF. Three probability maps representing GM, WM and CSF, segmented from the 3D T1W images, were re-aligned and re-sliced to the space of the 3D individual volumes of the DCE-MRI of the subject. WM and GM masks were generated using a probability cutoff of 0.975 , and these masks were then used for subsequent quantitative analysis. Figure 1b shows the segmented GM, WM, and tumor mask overlaid on the aligned last frame of the 3D LDHT and FDHS.

\section{Measurement of Vascular Input Function (VIF)}

Estimation of absolute CBF requires identification of a suitable AIF, and for practical purposes, a good approximation may be achieved by measuring the input function in the superior sagittal sinus (SSS) $)^{3,17}$. Our VIF measurement method for the T1W LDHT data has been previously described and utilizes a semi-automatic extraction method, to identify voxels within the SSS that display maximum enhancement during the first pass of the CA bolus ${ }^{18}$.

In order to investigate variations in the shape of VIFs from individually measured $C_{\mathrm{b}}(t)$ curves we retrospectively inspected VIFs from all previous LDHT T1W DCE MRI studies performed in our laboratory that used the same injection protocol. In total 55 VIFs from 55 visits of 36 patients with NF2 $(n=20)$, sporadic VS $(n=7)$, and GBM $(n=9)$ were analyzed. All participants had consented for later retrospective analysis of their data. 
We examined variations in the VIF to identify the range in the number of measurement points that can be identified in the early time points window.

Data from the $\mathrm{T} 2 * \mathrm{~W}$ DSC acquisition was processed using the commercially available software tool (MIStar, Apollo Medical Imaging, Melbourne, Australia), which incorporates an automated AIF detection algorithm. This algorithm performs pixelwise calculation of bolus arrival time, height, width and area under curve (AUC) of the $\triangle \mathrm{R} 2 *$ signal, and identifies the AIF as the cluster of pixels which show early arrival, large AUC, high peak height and narrow peak width.

\section{The Microsphere Model}

A prerequisite for the application of the microsphere theory is "sufficient organ retention" ${ }^{\underline{3}}$. In fact, for a time period less than the minimum intravascular transit time, any indicator behaves like a microsphere, in that no indicator that has arrived in an organ will have yet left it. During this time, the organ 'collects' counts, i.e. performs a 'biological' integration of the arterial counts. 'Mathematical' integration of the arterial counts, i.e. a running sum of the frame-by-frame counts, therefore generates a curve which has the same shape as the organ curve ${ }^{2}$. Mathematically, the microsphere model can be written as:

$$
C_{t}(t)=f \cdot \int_{0}^{t} C_{b}\left(t^{\prime}\right) d t^{\prime} \quad \text { with } t \in E T W, \quad[1]
$$


where the tissue GBCA concentration, $\mathrm{C}_{\mathrm{t}}(t)$, is equal to the amount of GBCA delivered to $1 \mathrm{ml}$ of tissue by time $t, f$ is the perfusion term (usually expressed as $\mathrm{ml}$ minute $\mathrm{ml}^{-1} \mathrm{ml}^{-1}$ and $\mathrm{C}_{\mathrm{b}}(t)$ is the arterial blood concentration (input function).

Then, according to the fundamental theorem of calculus, we have

$$
\frac{d C_{t}(t)}{d t}=f \cdot C_{b}(t)
$$

and

$$
\max \left(\frac{d C_{t}(t)}{d t}\right)=f \cdot \max \left(C_{b}(t)\right)
$$

Eq. 3 implies that the maximum gradient of the upslope of the first-pass $\mathrm{C}_{\mathrm{t}}(t)$ is reached at the same time as the regional arterial peak under the microsphere prerequisite:

$$
t_{M G}=t_{A I F_{-} \text {peak }} \quad \text { with } t \in E T W
$$

where $t_{\mathrm{MG}}$ and $t_{\mathrm{AIF} \_ \text {peak }}$ are the time to the maximum gradient of $\mathrm{C}_{\mathrm{t}}(t)$ and the time to the peak of arterial input function (AIF), respectively.

The MG method for blood flow derivation is then expressed as:

$$
f=\max \left(\frac{d C_{t}(t)}{d t}\right) / \max \left(C_{b}(t)\right)
$$

\section{The New T1W-ET Methods For Absolute CBF Estimation}

The new T1W-ET methods are based on the following two hypotheses: 
I) With a low dose compact bolus, the whole upslope segment prior to the first pass peak of the tissue concentration-time curves can be taken as the early time window (ETW), and the working data range for the CBF measurement.

II) When the effects of noise are considerable, an averaged concentration (AC) based method, especially when applied on data points located in a segment with higher ENR, is superior to a MG based method.

To assess the validity of our low dose T1W DCE MRI protocol for CBF evaluation using the microsphere model, i.e. whether Eq. 1 does hold true for our data, we tested whether the integrated input curve ( $\left(\mathrm{IN}_{\text {aif }}\right)$ could be scaled so that it paralleled (or aligned after time shifting) the rising bolus time course of the tissue uptake curve, and if the required scaling factor was within the expected range of the cerebral blood flow $(f)$ for the type of the tissue tested.

The first step of the T1W-ET methods is to identify the first pass peak point of the tissue concentration-time curve, which is the point of maximum enhancement within the $30 \mathrm{~s}$ time period following the bolus arrival time of the global AIF. The two consecutive data points which display the greatest difference in tissue enhancement within the time segment between the AIF bolus arrival and the first pass peak point, are then found. Five different ways of manipulating the rising bolus concentration time course were compared for absolute $\mathrm{CBF}$ evaluation: 
1) The classical maximum gradient (MGclassical) method - the two consecutive data points which display the greatest difference in tissue enhancement on the rising bolus time course are identified. The maximum gradient is calculated as $\left(\Delta \mathrm{C}_{\mathrm{t}}(t)\right)_{\max } / \Delta \mathrm{t}$, and used in Eq [5] to determine CBF.

2) The upslope method (the slope method) - the two data points, i and $i+1$, displaying the greatest difference in enhancement are identified and the slope over these two points and two adjacent points $[i-1, i, i+1, i+2]$ is estimated by linear regression. This slope is then used as the numerator in Eq. [5] for calculating CBF.

The next two methods use the running average of three consecutive data points as the value of $\mathrm{C}_{\mathrm{t}}(t)$ in Eq. [1] for CBF evaluation. Both methods choose a reference time point $\left(t_{\text {ref }}\right)$ other than the time of bolus arrival (TOA), and identify data points located on the upper part of the rising bolus time course (a segment with higher ENR).

3) Averaged concentration referencing $t_{\mathrm{MG}}$ (the ACrMG method), where $t_{\mathrm{MG}}=\left(t_{\mathrm{i}}+\right.$ $\left.t_{i+1}\right) / 2$. The running average of three data points $[i+1, i+2, i+3]$ was used as the value of $\mathrm{C}_{\mathrm{t}}(t)$, therefore $t=t_{\mathrm{i}+2}=t_{\mathrm{MG}}+1.5 \cdot(\Delta t)=t_{\mathrm{AIF} \_ \text {peak }}+1.5 \cdot(\Delta t)$ in Eq. [1] The value of $t_{\mathrm{AIF} \_ \text {peak }}$ was found from the gamma variant fit of the $C_{\mathrm{b}}(t)$.

4) Averaged concentration referencing $t_{\text {peak }}$ (the ACrPK method), where $t_{\text {peak }}$ was the tissue peak time. If the time point for the tissue peak was $i_{\text {peak }}$, the running average of three data points $\left[\mathrm{i}_{\text {peak }}-1, \mathrm{i}_{\text {peak }}-2, \mathrm{i}_{\text {peak }}-3\right]$ was used as the value of $\mathrm{C}_{\mathrm{t}}(t)$. For 
convenience, we used $t=t_{\text {AIF_peak }}+1.5 \cdot(\Delta t)$ as the upper time limit in integration of AIF, as same as in the ACrMG method.

5) Finally, based on the results from Monte Carlo error analysis of the above four methods, we developed a new method for calculation of the averaged concentration. The new method takes the average of the CBF values obtained from the ACrMG and ACrPK methods. We called the combined method the ACcomb method.

We denoted the absolute $\mathrm{CBF}$ estimated using the five methods as $\mathrm{T} 1 \mathrm{~W}-\mathrm{CBF}_{\mathrm{ET}}$ which comprises $\mathrm{CBF}_{\mathrm{ACrMG}}, \mathrm{CBF}_{\mathrm{ACrPK}}, \mathrm{CBF}_{\mathrm{ACcomb}}, \mathrm{CBF}_{\mathrm{MGclassical}}$, and $\mathrm{CBF}_{\text {slope, }}$, respectively.

\section{Monte Carlo Simulation For Error Analysis}

Monte Carlo simulation was used to investigate the effects of noise on the CBF values estimated with the five T1W-ET methods. The WM and GM GBCA concentration curves were simulated based on the microsphere model and the hypothesis that the ETW (i.e., the working data range for the CBF measurement) is the whole upslope segment prior to the first pass peak of the tissue concentration-time curves.

The synthesized WM and GM contrast agent concentration curves (see below), with 'true' $\mathrm{CBF}_{\mathrm{WM}}=25 \mathrm{ml} / \mathrm{min} / 100 \mathrm{ml}$ and 'true' $\mathrm{CBF}_{\mathrm{GM}}=60 \mathrm{ml} / \mathrm{min} / 100 \mathrm{ml}$ respectively, were converted back into SI-time curves based on the in vivo mean baseline SI, the precontrast $\mathrm{T} 1$ relaxation time $\left(T_{10}\right)$, and a literature value of longitudinal relaxivity $(4.39$ 
$\left.\mathrm{mM}^{-1} \mathrm{~s}^{-1}\right)^{\frac{19}{}}$. The generated SI-time courses were sampled with a temporal resolution of 1.0 second, and Rician white noise with noise level (= standard deviation/ mean baseline signal) of $1 \%, 2 \%, 3 \%, 4 \%$ and $5 \%$ respectively was added to the simulated SI-time curves. Absolute CBF values were calculated using the synthetic data sets to produce the so-called 'measured' values with the five estimation methods respectively. Percent deviations $(\mathrm{PD})$ of the 'measured' values from the 'true' values were calculated as: $\mathrm{PD}=$ (measured - true)/true $100 \%$. 20000 repetitions were performed for each method to produce mean and standard deviation (SD) of PD for each CBF estimates.

\section{In Vivo Data Processing}

$\mathrm{T} 1 \mathrm{~W}-\mathrm{CBF}_{\mathrm{ET}}$ images were calculated for the 12 NF2 patients, the 7 sporadic VS patients, and for the one patient with a GBM. For the GBM patient, maps of T2*W-CBF and T2*W-CBV were generated from the DSC MRI using MIStar and the singular value decomposition (SVD) deconvolution method of Ostergaard et al ${ }^{20}$. Previous authors have

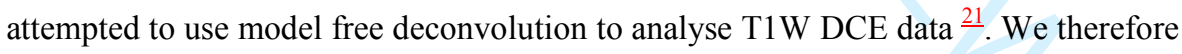
also analysed the LDHT DCE-MRI data from our GBM patient using a model free SVD deconvolution approach and compared these derived values with values obtained using the $\mathrm{T} 1 \mathrm{~W}-\mathrm{CBF}_{\mathrm{ET}}$ and $\mathrm{T} 2 * \mathrm{~W}-\mathrm{CBF}$ approaches.

We also carried out a tracer kinetic analysis on the T1W-DCE MRI data using the extended Tofts model (ETM) $)^{\frac{22,23}{2}}$, to yield fractional plasma volume $\left(v_{\mathrm{p}}\right)$ and other physiological parameters such as the transfer constant $K^{\text {trans }}$. Figure 1c shows representative $\mathrm{CBF}_{\mathrm{ACcomb}}$ images of a patient with NF2 alongside maps of $v_{\mathrm{p}}$ and $K^{\text {trans }}$ 
derived using the LDHT and FDHS acquisitions of the ICR-DICE ${ }^{14}$. As can be seen from

Fig 1c, the LDHT derived $K^{\text {trans }}$ map is free from vessel artifacts, whereas the $K^{\text {trans }}$ map derived from the FDHS showed greater tumor heterogeneity detail thanks to the higher spatial resolution but at the expense of vessel artifacts due to overestimation of $K^{\text {trans }}$ in areas of high $v_{\mathrm{p}}$ resulting from the low temporal resolution $(\Delta \mathrm{t}=10 \mathrm{~s})$.

For direct comparison between various parametric matrices, a data processing pipeline was constructed using SPM scripts ${ }^{16}$ to allow intra-subject spatial alignment between various MR images and derived parametric maps. Segmented tissue masks (WM, GM, CSF, and tumor respectively) were then applied onto parametric maps for generating ROI mean values, or for pixel-by-pixel comparison between multi-parametric maps. For repeated studies, longitudinal spatial alignment was also performed using the ending frame, i.e. the last 3D volume of the LDHT or FDHS DCE series acquired on day 0 as the destiny of the co-registration for all other images of the patient at day0 or day90. The comprehensive image spatial alignment between the T2*W-DSC and T1W-DCE images facilitated more convenient visual inspection and pixel-by-pixel comparison of $\mathrm{T} 2 * \mathrm{~W}$ $\mathrm{CBF}$ and $\mathrm{T} 1 \mathrm{~W}-\mathrm{CBF}_{\mathrm{ET}}$ maps.

\section{Statistical Analysis}

The accuracy and precision of the five methods were compared by Monte Carlo simulation of the mean and SD of percent deviations for $\mathrm{CBF}$ estimates at varying levels of Rician noise. 
Using the LDHT T1W DCE and T2*W DSC-MRI data from the patient with a GBM, we investigated the concordance in the relationships of $\mathrm{T} 2 * \mathrm{~W}-\mathrm{CBF}$ vs. T2*W-CBV and $\mathrm{T} 1 \mathrm{~W}-\mathrm{CBF}_{\mathrm{ACcomb}}$ vs. $v_{\mathrm{p}}$ in tumor on a pixel-by-pixel basis. Pixel scatter plots and linear regression analysis were further used to assess concordance of intratumoral $\mathrm{T} 1 \mathrm{~W}-\mathrm{CBF} \mathrm{ET}_{\mathrm{ET}}$ and $\mathrm{T} 2 * \mathrm{~W}-\mathrm{CBF}$ estimates and to assess the intratumoral pixelwise relationship of $\mathrm{T} 2 * \mathrm{~W}$ CBF compared to $\mathrm{T} 2 * \mathrm{~W}-\mathrm{CBV}$, and $\mathrm{T} 1 \mathrm{~W}-\mathrm{CBF}_{\mathrm{AC} c o m b}$ compared to $v_{\mathrm{p}}$. Pixelwise concordance between the derived T1W(SVD)-CBF estimates and T1W-CBF $\mathrm{ET}$ and $\mathrm{T} 2 * \mathrm{~W}-\mathrm{CBF}$ data is shown in supplementary data.

In order to assess the reproducibility of the ACcomb method, mean GM and WM CBF values were calculated from each MRI scan, for the 7 sporadic VS patients who underwent two consecutive DCE-MRI acquisitions. The reproducibility of each pairwise comparison was then assessed using the test-retest coefficient of variation (CoV). For each subject, $\mathbf{i}$, the $\mathrm{CoV}$ is the standard deviation, $\boldsymbol{\sigma}_{\mathbf{i}}$, for the two measurements on that subject, divided by the mean-volume, $\boldsymbol{\mu}_{\mathbf{i}}$, for the subject. The overall test-retest CoV for a group of $\mathbf{N}$ subjects is then $\underline{24,25}$

$\sqrt{\sum_{i}\left(\sigma_{i} / \mu_{i}\right)^{2} / N}$.

To compare the pre- and post-treatment values of CBF in patients with NF2, the average CBF values of GM, WM, and tumor (VS) over the whole-volume ROIs were calculated for each visit of each patient, using the five T1W-ET methods respectively. A paired ttest was used to compare the group mean values on day 0 and day90. To reduce the potential for Type I errors through multiple comparisons using the five T1W-ET 
methods, the standard significance level of $\mathrm{P}=0.05$ was adjusted using the Bonferroni correction $(\mathrm{C}=5)$ to achieve a family-wise error rate $(\mathrm{FEWR})$ of no more than $5 \%$.

\section{RESULTS}

\section{The VIF and the Tissue Concentration Curves Within the ETW (Hypothesis 1) From} the LDHT T1W-DCE MRI Fulfills the Requirements of the Microsphere Model

Figure 2 shows variation in the shape of $C_{\mathrm{b}}(t)$ curves measured from the superior sagittal sinus (SSS) of different individuals, when using the power injector with the same GBCA dose and injection rate. Of the 55 MRI exams studied 92.7\%, had either 5 (43.6\%), 6 $(38.2 \%)$, or $7(10.9 \%)$ data points on the upslope segment prior to the first pass peak of the measured $C_{\mathrm{b}}(t)$ curves.

For a study using the microsphere model, the validity of the technical acquisition needs to be checked by ensuring that the integrated input curve, multiplied by the tissue blood flow, parallels to that of the tissue time-density curve, thus fulfilling one of the requirements of the model $l^{1-3}$. Figures $3 \mathrm{a}$ and $3 \mathrm{~b}$ demonstrate an example of this. $\mathrm{INT}_{\text {aif }}$ was calculated by integration of the gamma variant fit of the $C_{\mathrm{b}}(t)$; the measured WM and GM curves were averaged concentration-time curves from the whole-volume ROIs, which were automatically defined from the WM and GM masks respectively. In Fig. 3a, the $\mathrm{INT}_{\text {aif }}$ was time-shifted and scaled to align with the rising bolus time course of the WM concentration curve, resulting in a calculated $f_{\mathrm{wm}}$ of $25 \mathrm{ml} / \mathrm{min} / 100 \mathrm{ml}$. In Fig. $3 \mathrm{~b}$, the 
$\mathrm{INT}_{\text {aif }}$ was time-shifted and scaled to align with the rising bolus time course of the GM concentration curve, resulting in a calculated $f_{\mathrm{gm}}$ of $60 \mathrm{ml} / \mathrm{min} / 100 \mathrm{ml}$.

Figures $3 \mathrm{c}$ and $3 \mathrm{~d}$ show a simulation of the tissue concentration curves based on the microsphere model. The flow-scaled INT ${ }_{\text {aif }}$ and ROI-averaged WM and GM concentration curves used in the simulation were the same as in Figs. 3a and 3b. The upslope part of the theoretical tissue curve (the working data range, ETW, for CBF measurement) was sampled from the flow-scaled $\mathrm{INT}_{\text {aif }}$, while keeping the downslope part, starting from and including the tissue peak time point, of the measured tissue curve.

\section{Averaged Concentration Methods Performed Better Than Upslope or Maximum}

\section{Gradient Methods on Monte Carlo Simulations}

Figure 4 compares percent deviation (mean and $\mathrm{SD}$ ) in $\mathrm{CBF}_{\mathrm{WM}}$ and $\mathrm{CBF}_{\mathrm{GM}}$ derived from ACrMG, ACrPK, ACcomb, upslope, and the traditional MG methods, using various noise levels. The traditional MG method yielded poor accuracy and precision even at small noise levels for simulated WM and GM curves. The upslope method showed better accuracy and precision than the MG method but poorer precision than the averagedconcentration methods, especially at noise levels higher than 3\%. For noise levels higher than $2 \%$, the $\mathrm{CBF}_{\mathrm{WM}}$ estimates obtained from the ACrMG and the ACrPK methods behaved oppositely: the ACrMG analysis (green line) overestimates while the ACrPK (blue line) underestimates $\mathrm{CBF}_{\mathrm{WM}}$. The $\mathrm{ACcomb}$ method, which is the average of the $\mathrm{ACrMG}$ and $\mathrm{ACrPK}$ values, estimates $\mathrm{CBF}_{\mathrm{WM}}$ more accurately, and reduces the $\mathrm{SD}$ of 
$\mathrm{PD}$ in $\mathrm{CBF}_{\mathrm{WM}}$ estimation (Figures $4 \mathrm{a}$ and $4 \mathrm{~b}$ ). The $\mathrm{CBF}_{\mathrm{GM}}$ estimates (Figures $4 \mathrm{c}$ and $4 \mathrm{~d}$ ), showed much less variation in the three averaged-concentration methods, which may be due to the more than twofold greater ENR in the GM uptake curves relative to the WM curves for the same noise level. The overall performance of the ACcomb method was better than the other two averaged-concentration methods (ACrMG and ACrPK) at a noise level of $4 \%$ or higher, but consistently underestimated $\mathrm{CBF}_{\mathrm{GM}}$ by about $5 \%$. For noise levels $<4 \%$, the accuracy of $\mathrm{CBF}_{\mathrm{ACrPK}}$ became close to, or better than that of $\mathrm{CBF}_{\mathrm{ACcomb}}$. Furthermore, comparing Fig. $4 \mathrm{a}$ with $4 \mathrm{c}$ revealed that $\mathrm{CBF}_{\mathrm{GM}} / \mathrm{CBF}_{\mathrm{WM}}$ obtained by ACcomb would be on average around 5\% lower than the 'true' $\mathrm{CBF}_{\mathrm{GM}} / \mathrm{CBF}_{\mathrm{WM}}$, while $\mathrm{CBF}_{\mathrm{GM}} / \mathrm{CBF}_{\mathrm{WM}}$ obtained by $\mathrm{ACrPK}$ would be on average $[2 \%$, $5 \%, 11 \%, 14 \%, 15 \%]$ higher than the 'true' $\mathrm{CBF}_{\mathrm{GM}} / \mathrm{CBF}_{\mathrm{WM}}$ with the error increasing with increasing noise level $([0.01,0.02,0.03,0.04,0.05$, respectively $)\}$. This was because, although $\mathrm{ACrPK}$ underestimated both $\mathrm{CBF}_{\mathrm{GM}}$ and $\mathrm{CBF}_{\mathrm{WM}}$, the size of the negative $\mathrm{PD}$ of $\mathrm{CBF}_{\mathrm{WM}}$ was larger than that of $\mathrm{CBF}_{\mathrm{GM}}$.

\section{Noise Levels For the In Vivo Pixel SI Curves Are Consistent With the Noise Levels}

\section{Employed In the Simulation}

Figure 5 shows in vivo signal intensity (SI) curves for GM and WM derived from individual voxels (Fig 5a and 5b) and ROIs placed within the GM and WM respectively (see Fig $5 \underline{\text { de }}$ and $5 \underline{e}$ d), whereas Fig 5 f shows the vascular input function. The SI baseline mean, standard deviation, noise level (= SI baseline SD/mean), ESNR and the estimated

CBF values are shown on the panel for each of the tissue pixel/ROI SI curves. As can be 
seen, the noise levels for the pixel SI curves acquired from a 1.5T scanner show around $4 \%$ or less, consistent with the noise levels employed in the simulation.

\section{Averaged Concentration Methods Provide More Accurate Estimation of In Vivo CBF Values Than Classical Maximum Gradient (MG)/Upslope Methods}

Figure 6a shows the CBF images derived using the LDHT T1W DCE-MRI (the left five columns) and the T2*W DSC-MRI (the right column) acquired at 3T from a patient with a right sided GBM. The left hand panel shows representative axial section taken from the acquired whole brain $3 \mathrm{D} \mathrm{CBF}_{\mathrm{AC} c o m b}$ images. Using the $\mathrm{ACcomb}$ method, the calculated mean CBF value was $75.3 \mathrm{ml} / \mathrm{min} / 100 \mathrm{ml}$ for $\mathrm{GM}$ and $32.3 \mathrm{ml} / \mathrm{min} / 100 \mathrm{ml}$ for $\mathrm{WM}$, giving a $\mathrm{CBF}_{\mathrm{GM}} / \mathrm{CBF}_{\mathrm{WM}}$ ratio of 2.33. The derived $\mathrm{CBF}$ maps using the $\mathrm{ACrMG}$ and $\mathrm{ACrPK}$ methods are visually similar to the ACcomb method, but as shown in Figure 6a there is over-estimation of the mean CBF values of GM and WM when using the classical MG and the upslope methods. The mean ROI CBF values of the GM, WM and tumor derived from the five methods are listed in Table 1. Spatial alignment of the T2*W DSC-MRI to their T1W counterparts (see Figure 6a), showed expected differences in appearances of the vasculature within both the 'normal' brain and the tumor itself due to the susceptibility effects of intravascular contrast in $\mathrm{T} 2 * \mathrm{~W}$ images. The mean values of the $\mathrm{T} 2 * \mathrm{~W}-\mathrm{CBF}$ and those of $\mathrm{T} 1 \mathrm{~W}-\mathrm{CBF}_{\mathrm{ET}}$ derived by the AC-based methods for both GM and WM are globally compatible, however, as shown in Table 1. 


\section{Close Intratumoral Pixel-by-Pixel Correlation Between T1W-CBF $\mathrm{ACcomb}_{\text {and }}$ Estimates of $v_{p}$ Derived From Extended Tofts Model}

Figure $6 \mathrm{~b}$ shows the central slice of the $3 \mathrm{D} v_{\mathrm{p}}$ and T2*W-CBV maps from the patient with a GBM. The depicted tumor and brain vasculature on the $v_{\mathrm{p}}$ map are visually very similar to the $\mathrm{T} 1 \mathrm{~W}-\mathrm{CBF}_{\mathrm{AC} \text { comb. This }}$ is in concordance with the similarity observed between the $\mathrm{T} 2 * \mathrm{~W}-\mathrm{CBV}$ and $\mathrm{T} 2 * \mathrm{~W}-\mathrm{CBF}$ maps. Figure $6 \mathrm{~b}$ also displays the scatter plots of pixel values of $v_{\mathrm{p}}$ vs T1W-CBF $\mathrm{ACcomb}$ and $\mathrm{T} 2 * \mathrm{~W}-\mathrm{CBV}$ vs $\mathrm{T} 2 * \mathrm{~W}-\mathrm{CBF}$ from the tumor ROI. Visual inspection supported the use of a simple linear regression model, which showed a close correlation between $\mathrm{T} 1 \mathrm{~W}-\mathrm{CBF}_{\mathrm{AC} \text { comb }}$ and $v_{\mathrm{p}}\left(\mathrm{R}^{2}=0.934\right)$. A similar relationship was found between $\mathrm{T} 2 * \mathrm{~W}-\mathrm{CBV}$ and $\mathrm{T} 2 * \mathrm{~W}-\mathrm{CBF}\left(\mathrm{R}^{2}=0.853\right)$. Nevertheless, the scatterplot of tumor voxels of maps of $\mathrm{T} 1 \mathrm{~W}-\mathrm{CBF}_{\mathrm{AC}}$ omb vs. T2*W-CBF and their linear regression displayed a much weaker relationship $\left(\mathrm{R}^{2}=0.263\right)$.

\section{CBF Estimation Using T1W(SVD) Approach Overestimates Tumor CBF}

As can be seen in Table 1, when using an ROI analysis with parametric maps, T1W (SVD) methods gave mean CBF values for WM and GM compatible with the T2*WSVD and our T1W-CBF-ET method, but overestimated CBF in the tumor itself. Our pixelwise analysis is shown in supplementary data, and showed a close pixelwise correlation between the T1W(SVD) $\mathrm{T} 1 \mathrm{~W}-\mathrm{CBF}_{\mathrm{AC} \text { comb }}$ estimates for both GM and WM. 


\section{Good Reproducibility of the ACcomb Method Reported In Terms of CoVs}

Table 2 details the test-retest $\mathrm{CoV}$ for $\mathrm{CBF}_{\mathrm{ACcomb}}$ obtained from the seven patients with sporadic VSs. As can be seen the overall test-retest CoV was 5.76 and 8.51 for NAWM and NAGM respectively, showing overall good reproducibility of the $\mathrm{CBF}_{\mathrm{AC} \text { comb }}$ measurements and better reproducibility for NAWM measurements.

\section{Average Concentration ET Methods Show Post-Treatment Increases In Normal Appearing WM CBF In NF2 Patients Treated With Bevacizumab}

Figure 7 shows CBF (top row) maps derived from a NF2 patient with a large left sided vestibular schwannoma and four meningiomas. The $v_{\mathrm{p}}$ images derived using the ETM are also displayed for comparison in the bottom row. Slices from three levels of the 3D parametric images are shown. As can be seen there is some reduction of CBF and $v_{\mathrm{p}}$ within the VS at 90 days and the appearances of the T1W-CBF $\mathrm{ACcomb}_{\text {maps }}$ and $v_{\mathrm{p}}$ maps are very similar at each time-point.

Table 3 lists the group mean values ( $\pm \mathrm{SD}$ ) of CBF for GM, WM, and $\mathrm{CBF}_{\mathrm{GM}} / \mathrm{CBF}_{\mathrm{WM}}$ respectively for the 12 patients with $\mathrm{NF} 2$ treated with bevacizumab. Estimated mean values on day0 and day90 using the five different ET methods, are listed. The ACcom $\underline{b}$ produced mean $\mathrm{CBF}_{\mathrm{GM}}$ of $55.9 \pm 13.9 \mathrm{~mL} / 100 \mathrm{~g} / \mathrm{min}$. $\mathrm{CBF}_{\mathrm{WM}}$ of $25.8 \pm 3.45 \mathrm{~mL} / 100 \mathrm{~g} / \mathrm{min}$ on day0, $\mathrm{CBF}_{\mathrm{GM}}$ of $61.0 \pm 8.28 \mathrm{~mL} / 100 \mathrm{~g} / \mathrm{min}$. 
$\mathrm{CBF}_{\mathrm{WM}}$ of $28.4 \pm 3.43 \mathrm{~mL} / 100 \mathrm{~g} / \mathrm{min}$ on day90. The ACcomb and ACrPK methods produced the highest $\mathrm{CBF}_{\mathrm{GM}} / \mathrm{CBF}_{\mathrm{WM}}$ ratios $(2.15-2.34)$, and the least intra-group $\mathrm{SD}$ for GM $(8.04-13.92)$, and WM $(3.06-3.45)$ respectively. With a paired t-test, both the ACbased methods, ACcomb and ACrPK, show a moderate increase in the group mean value of CBF in NAWM after treatment (Adjusted p values 0.03 and 0.005 respectively). Interestingly, neither the classical MG nor upslope method, show such changes in WM and GM CBF after treatment.

\section{DISCUSSION}

We present a new method based on the microsphere principle, for estimation of absolute CBF using a low dose high temporal T1W DCE MRI acquisition. This new method allows a more accurate and reliable estimation of absolute CBF, as instead of using a conventional MG-based algorithm, an averaged contrast agent concentration based method is used, which utilizes data points located in a higher ENR segment of the rising bolus time course.

Monte Carlo simulations demonstrated that these AC-based T1W-CBF $F_{\mathrm{ET}}$ methods provided more accurate estimates of CBF compared to the MG and slope methods, especially when the ENR is low, such as within normal appearing white matter. The mean CBF of GM was, however, underestimated when using the $\mathrm{ACrPK}$ and $\mathrm{ACcomb}$ methods. The observed $5 \%$ underestimation in $\mathrm{CBF}_{\mathrm{GM}}$ values using this new combined 
method is, however, in alignment with published simulation results, such as those of $\mathrm{Wu}$ et al. using deconvolution ${ }^{26}$, and those of Kwong et al. using the ET in DSC MRI ${ }^{7}$.

In vivo evaluation of this new $\mathrm{T} 1 \mathrm{~W}-\mathrm{CBF}_{\mathrm{ET}}$ algorithm in 20 patients showed that the $\mathrm{AC}$ based methods provided superior estimates of CBF compared to the MG and slope methods, with the classicat MG method produceding the poorest CBF estimates $\left(\mathrm{CBF}_{\mathrm{GM}} / \mathrm{CBF}_{\mathrm{WM}}\right.$ ratio less than 1.5$)$ whilst t. Both the ACcomb and $\mathrm{ACrPK}$ methods for ealeulating $\mathrm{T} 1 \mathrm{~W}-\mathrm{CBF}_{\mathrm{ET}}$-produced the mosta more realistic -reasonable $\mathrm{CBF}_{\mathrm{GM}} / \mathrm{CBF}_{\mathrm{WM}}$ ratio (average $2.15-2.52$ ). The $\mathrm{CBF}_{\mathrm{WM}}$ calculated by $\mathrm{ACrPK}$ was lower than that produced by $\mathrm{ACcomb}$; and the $\mathrm{CBF}_{\mathrm{GM}}$ calculated by $\mathrm{ACrPK}$ was lower than that by ACcomb for DCE MRI data acquired on a-1.5T scannerdata(Table 3), but higher than that by ACcomb for DCE MRI for 3T data-aequired on a 3.0T seanner (Table 1). The $\mathrm{CBF}_{\mathrm{GM}} / \mathrm{CBF}_{\mathrm{WM}}$ ratio produced by $\mathrm{ACrPK}$ (2.52 and 2.30 for PCE data aequired on $3.0 \mathrm{~T}$ and $1.5 \mathrm{~T}$ seanner data respectively) was higher than that by from ACcomb (2.33 and 2.15 for 3.0T and $1.5 \mathrm{~T}$ data respectively for $\mathrm{DCE}$ data acquired on $3.0 \mathrm{~T}$ and $1.5 \mathrm{~T}$ seanner respectively). These in vivo observations were consistent with the Monte Carlo simulations, and can be attributed to the considering the generally poorerlower ENR on $1.5 \mathrm{~T}$ compared with $3.0 \mathrm{~T}$ seanner $^{13}$.

A correlation between $\mathrm{CBF}$ and $\mathrm{CBV}$ in both normal brain tissue $\mathrm{e}^{21,27}$ and gliomas ${ }^{28}$ has

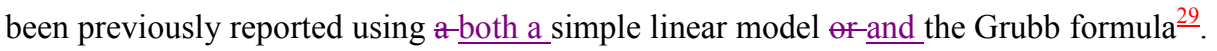
In our study we compared the relationships between $\mathrm{T} 2 * \mathrm{~W}-\mathrm{CBF}$ ss-and $\mathrm{T} 2 * \mathrm{~W}-\mathrm{CBV}$ relationship-and the-between $\mathrm{T} 1 \mathrm{~W}-\mathrm{CBF}_{\mathrm{ACcomb}} \mathrm{ts}$-and $v_{\mathrm{p}}$ relationship-on a pixel-by-pixel 
basis within a high grade glioma. Both pairs were highly correlated, consistent with previous results ${ }^{\underline{28}}$. On the other hand, there was a weak pixel wise correlation between the ET derived T1W-CBF and deconvolution derived T2*W-CBF maps. This discrepancy may be due in part to the fundamental differences in mechanism between T1 relaxivity

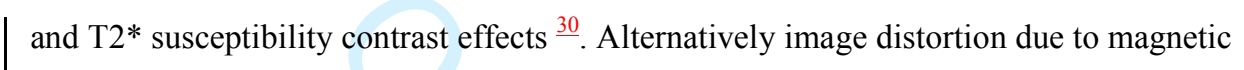
susceptibility effects, especially when using fast T2*W-DSC imaging techniques may limit accurate coregistration of T1W-DCE and T2*W-DSC images thereby adversely affecting pixelwise correlations $\underline{31,32} \underline{33}$. Indeed the relatively good concordance between AC based $\mathrm{T} 1 \mathrm{~W}-\mathrm{CBF}_{\mathrm{ET}}$ and deconvolution derived $\mathrm{T} 2 * \mathrm{~W}-\mathrm{CBF}$ values when using a $\mathrm{ROI}$ analysis shown in Table 1, suggests that this may be the case.

In addition to providing more accurate reliable estimates of $\mathrm{CBF}$, the reproducibility of this new AC based method was shown through aestablished by test re-test analysis. The oOverall coefficient of variation $(\mathrm{CoV})$ for absolute $\mathrm{CBF}$ measured using the ACcomb method was $5.76 \%$ in the NAWM, and $8.51 \%$ in the NAGM. Our measured CoV eompares-compared favourably with a recent study utilising both $\mathrm{H}_{2} \mathrm{O}^{15}$ PET and contrast-enhanced perfusion_MR imaging, where the CoV across two scans taken 2 days apart was $8 \%$ vs $30 \%$ for white matter, and $10 \%$ vs $40 \%$ for grey matter respectively $y^{34}$.

Some authors have advocated the use of model free singular value decomposition approaches for CBF derivation from DCE-MRI data. There are, however, distinct advantages to the use of ET methods over SVD approaches. Firstly, T1W(SVD) can not distinguish signal contributions from intra- and extra-vascular space, and is thereby more 
affected by vessel leakage than the_CBF-ET methods. As shown in our data (see table 1),

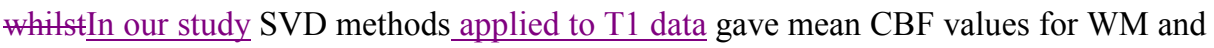
GM compatible comparable with theto those acquired with T2*W-SVD and our T1WCBF-ET method. However, in tumors, -there was an-overestimation of CBF in tumors, an effect we hypothesisehypothesize is due to BBB breakdown and contrast leakage. SecondlyIn addition, perfusion calculation by deconvolution is critically dependant on the data ENR ${ }^{7}$. In the work by Larsson et al $\stackrel{13}{ }$, T1W-DCE MRI data was acquired on a $3 \mathrm{~T}$ scanner with a GBCA dose of $0.05 \mathrm{mmol} / \mathrm{kg}$ to ensure sufficient ENR for pixelwise calculation of CBF using Tikhonov's procedure of deconvolution. Despite this, and the authors commented that the relatively poor ENR at $1.5 \mathrm{~T}$ prevented the calculation of CBF maps using this the deconvolution approach. $-\frac{35}{-}$ Through using data points located in a higher ENR segment of the rising bolus time course, however, our ET method dees not suffer less from this limitation.

The CBF increases demonstrated using the ACcom and ACrPK method in normal appearing WM (NAWM) at 90 days post bevacuzimab-bevacizumab treatment were statistically significant, and exceeded our demonstrated reproducibility threshold for WM CBF measurements. This suggests that these changes are genuine rather than due to reproducibility variation, and ${ }_{2}$ whilst this is a preliminary study of only 12 patients, these findings are biologically plausible, as the therapeutic effect of bevacizumab in this group is believed to result from alleviation of intracranial pressure due to reduction in intratumoural oedema ${ }^{36}$. as decreases in cerebral blood flow in "normal" appearing brain in 
Larger studies will, however, be needed, to further investigate bevacizumab treatment related changes in microcirculatory parameters of normal-appearing brain tissues.

The key advantages of our new AC-based T1W-ET methods can be outlined as below:

1) Application of T1W-ET in leaky tissue. The T1W-ET method is less vulnerable to confounding resulting from leakage, re-circulation, and back flux $\stackrel{7,11}{\text {. }}$

2) Improved robustness to low signal to noise ratio. Through use of data points located in a higher ENR segment of the rising bolus time course, the AC-based T1W-ET method allows pixel-by-pixel calculation of CBF using T1W-DCE MRI acquired at both $1.5 \mathrm{~T}$ and $3 \mathrm{~T}$ scanners, with a GBCA dose as low as 0.02 $\mathrm{mmol} / \mathrm{kg}$.

3) Simplified data processing. When using the AC-based T1W-ET methodology there is no need to measure TOA, de-noise data, or correct for leakage and recirculation.

4) Acquiring 3D DCE-MRI covering the whole brain. A time resolution of $1 \mathrm{~s}$ was chosen in this study, allowing averaging of three GBCA concentration data points when using the new T1W-ET methods, whilst permitting acquisition of 3D DCE images covering the whole brain.

5) No covariance error due to multi-parameter fitting procedure. Calculation of $\mathrm{CBF}$ with ACcomb does not require multi-parametric fitting, which is prone to covariance errors and 'salt-and-pepper' noise $\mathrm{s}^{\frac{37}{}}$. The generation of $\mathrm{CBF}_{\mathrm{AC} \text { comb }}$ 
maps does not require filtering, in contrast to the maps generated using the twocompartment exchange model ${ }^{37}$.

Finally, one important advantage of the new method is that it allows a lower dose of GBCA to be used compared to other methods of determining CBF such as DSC-MRI. To successfully utilize the microsphere model in determining CBF, a low-dose compact contrast bolus injection is optimum to ensure there is no efflux of intravascular tracer before the first pass AIF peak and to enable better determination of the arterial input function peak ${ }^{20}$. Reduced contrast dose is also-a pertinent clinical concern, as the potential nephrotoxicity of full dose GBCA is well recognized $\frac{38}{3}$, and there is growing evidence that gadolinium deposition may occur in the brain following repeated

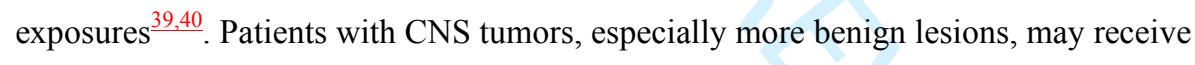
many contrast enhanced MR scans throughout their lifetime. As such, an MR acquisition method which permits derivation of accurate perfusion metrics using a lower dose of contrast agentmethod, which permits derivation of accurate perfusion metrics using a lower dose of contrast agent, may be of high clinical utility.

There are some limitations in our study. Firstly, the new AC-based methods for CBF measurements were evaluated in only a small cohort of patients with NF2 and one patient with a GBM. Secondly, the 3D whole brain acquisition used in the study comes at the expense of lower spatial resolution than methods utilized by other authors, who acquired only 4-10 slices $^{7}, \frac{21,37}{}$. Finally, a uniform value of hematocrit was used in this study, despite expected inhomogeneities in intra- and inter-subject hematocrit. Because 
measurements of regional cerebral blood flow are dependent upon regional hematocrit, any alteration in this may produce errors in the calculation of regional blood flow.

In conclusion, we have developed and assessed a new early time points (ET) method of estimating absolute CBF using low dose high temporal (LDHT) DCE MRI data. Monte Carlo analysis shows that this new method improves the accuracy of measured absolute CBF values at different noise levels. In vivo application of this new method showed that the acquired $\mathrm{T} 1-\mathrm{CBF}_{\mathrm{ET}}$ maps displayed excellent gray-white matter flow contrast using a much smaller dose of GBCA than is used for conventional DSC experiments, and the measured values of WM and GM CBF using our new method matched perfusion values in literature. The typical test-retest coefficients of variation observed in this study suggest that T1W-ET measured CBF have sufficient reproducibility to be used in longitudinal studies, especially if large changes due to therapeutic intervention are expected, In a cohort of patients with NF2 undergoing treatment with bevacizumab, there was a moderate increase in CBF of normal-appearing white matter 90 days post therapy. Our new method offers advantages over currently used non-invasive methods of CBF measurement, and may have considerable future utility in clinical perfusion imaging. 


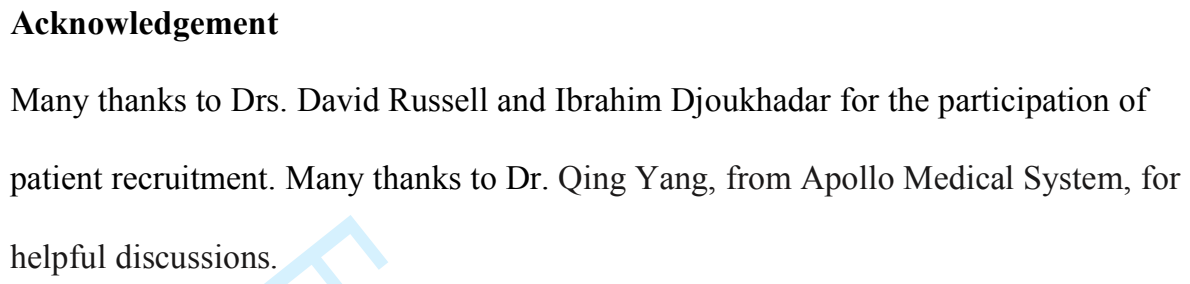




\section{Appendix A. Supplementary Data}

Supplementary data to this article can be found online at DOI: $10.17632 / \mathrm{hg7vppf6g5.1}$ 


\section{Glossary}

\begin{tabular}{|c|c|c|}
\hline Symbols & Interpretation & unit \\
\hline AIF & Arterial input function & $\mathrm{mmol} / \mathrm{ml}$ \\
\hline $\mathrm{C}_{\mathrm{b}}(t)$ & Blood CA concentration curve & $\mathrm{mmol} / \mathrm{ml}$ \\
\hline $\mathrm{C}_{\mathrm{t}}(t)$, & Tissue CA concentration curve & $\mathrm{mmol} / \mathrm{ml}$ \\
\hline $\mathrm{CBF}$ & Absolute-Ceerebral blood flow & $\mathrm{ml} / \mathrm{min} / 100 \mathrm{ml}$ \\
\hline $\mathrm{rCBF}$ & Relative CBF & None \\
\hline CBV & Absolute-Ceerebral blood volume & $\begin{array}{l}\mathrm{ml} / 100 \mathrm{ml} \\
\mathrm{ml} / 100 \mathrm{~g}\end{array}$ \\
\hline$C B F_{E T}$ & $\begin{array}{l}\text { Absolute CBF measured by the Early time (ET) } \\
\text { method }\end{array}$ & $\mathrm{ml} / \mathrm{min} / 100 \mathrm{ml}$ \\
\hline $\mathrm{CBF}_{\mathrm{ACcomb}}$ & $\begin{array}{l}\text { CBF measured using average of the CBF values } \\
\text { obtained from the ACrMG and ACrPK methods. }\end{array}$ & $\mathrm{ml} / \mathrm{min} / 100 \mathrm{ml}$ \\
\hline $\mathrm{CBF}_{\mathrm{ACrMG}}$ & $\begin{array}{l}\text { CBV measured using averaged concentration } \\
\text { referencing the time to maximum gradient }\end{array}$ & $\mathrm{ml} / \mathrm{min} / 100 \mathrm{ml}$ \\
\hline $\mathrm{CBF}_{\text {MGclassical }}$ & $\begin{array}{l}\text { CBF measured using classical Maximum Gradient } \\
\text { method. }\end{array}$ & $\mathrm{ml} / \mathrm{min} / 100 \mathrm{ml}$ \\
\hline $\mathrm{CBF}_{\mathrm{ACrPK}}$ & $\begin{array}{l}\text { CBF measured using averaged concentration } \\
\text { referencing time to peak }\end{array}$ & $\mathrm{ml} / \mathrm{min} / 100 \mathrm{ml}$ \\
\hline $\mathrm{CBF}_{\text {slope }}$ & CBF measured using upslope method & $\mathrm{ml} / \mathrm{min} / 100 \mathrm{ml}$ \\
\hline$\Delta t$ & Update time of DCE or DSC & $\mathrm{s}$ \\
\hline DCE MRI & Dynamic contrast enhancement MRI & \\
\hline
\end{tabular}




\begin{tabular}{|c|c|c|}
\hline DSC MRI & Dynamic susceptibility contrast enhancement MRI & \\
\hline ENR & Enhancement-to-noise ratio & \\
\hline ET & Early time method & \\
\hline ETM & Extended Tofts model & \\
\hline ETW & Early time window & \\
\hline $\begin{array}{l}\text { FDHS DCE } \\
\text { MRI }\end{array}$ & Full dose high spatial resolution DCE MRI & \\
\hline$f_{\mathrm{gm}}$ or $\mathrm{CBF}_{\mathrm{GM}}$ & Blood flow of grey matter & $\mathrm{ml} / \mathrm{min} / 100 \mathrm{ml}$ \\
\hline $\begin{array}{l}f_{\mathrm{wm}} \text { or } \\
\mathrm{CBF}_{\mathrm{WM}}\end{array}$ & Blood flow of white matter & $\mathrm{ml} / \mathrm{min} / 100 \mathrm{ml}$ \\
\hline GBCA & Gadolinium based contrast agent. & \\
\hline GBM & $\begin{array}{l}\text { Glioblastoma Multiforme (syn WHO grade IV } \\
\text { glioma) }\end{array}$ & \\
\hline HCT & Hematocrit. & none $(\%)$ \\
\hline $\mathrm{INT}_{\text {aif }}$ & Integral of AIF & \\
\hline $\begin{array}{l}\text { LDHT DCE- } \\
\text { MRI }\end{array}$ & Low dose high temporal resolution DCE MRI & \\
\hline MG & Maximum Gradient & \\
\hline NAWM & Normal-Appearing WM & \\
\hline PD & $\begin{array}{l}\text { Percentage deviation, } \mathrm{PD}=(\text { measured }- \text { true }) / \text { true } \mathrm{x} \\
100 \%\end{array}$ & \\
\hline PRESTO & (3D) echo-shifted multi-shot echo planar imaging & \\
\hline $\mathrm{R} 1_{\mathrm{N}}$ & Native longitudinal relaxation rate & $\mathrm{s}^{-1}$ \\
\hline
\end{tabular}




\begin{tabular}{|l|l|l|}
\hline ROI & Region of interest & \\
\hline SD & Standard deviation & \\
\hline SSS & Superior sagittal sinus & \\
\hline T1W & Longitudinal relaxation (T1) weighted (MR imaging) & \\
\hline T2*W & Effective transverse relaxation $\left(\mathrm{T} 2^{*}\right)$ weighted & \\
\hline$t_{\mathrm{AIF} p e a k}$ & Time to peak of AIF & $\mathrm{s}$ \\
\hline$t_{\mathrm{mg}}$ & Time to maximum gradient & $\mathrm{s}$ \\
\hline TOA & Time of arrival of contrast bolus & $\mathrm{s}$ \\
\hline$t_{\mathrm{peak}}$ & Time to peak & $\mathrm{s}$ \\
\hline$t_{\text {ref }}$ & Reference time point & $\mathrm{s}$ \\
\hline TR/TE & Repetition time and echo time & $\mathrm{ms} / \mathrm{ms}$ \\
\hline VIF & Vascular input function & $\mathrm{mmol} / \mathrm{ml}$ \\
\hline$v_{\mathrm{p}}$ & Vestibular Schwannoma $(\%)$ \\
\hline VS & & \\
\hline & & \\
\hline
\end{tabular}




\section{References}

1. Peters AM, Brown J, Hartnell GG, Myers MJ, Haskell C, Lavender JP. Noninvasive measurement of renal blood flow with 99mTc DTPA: comparison with radiolabelled microspheres. Cardiovasc Res 1987;21(11):830-834.

2. Peters AM. Fundamentals of tracer kinetics for radiologists. Br J Radiol 1998;71(851):1116-1129.

3. Koenig M, Klotz E, Luka B, Venderink DJ, Spittler JF, Heuser L. Perfusion CT of the brain: diagnostic approach for early detection of ischemic stroke. Radiology 1998;209(1):85-93.

4. Miles KA, Griffiths MR. Perfusion CT: a worthwhile enhancement? Br J Radiol 2003;76(904):220-231.

5. Nitzl D, Ohlerth S, Mueller-Schwandt F, Angst A, Roos M, Kaser-Hotz B. Dynamic computed tomography to measure tissue perfusion in spontaneous canine tumors. Vet Radiol Ultrasound 2009;50(4):347-352.

6. Moody AR, Martel A, Kenton A, et al. Contrast-reduced imaging of tissue concentration and arterial level (CRITICAL) for assessment of cerebral hemodynamics in acute stroke by magnetic resonance. Invest Radiol 2000;35(7):401-411.

7. Kwong KK, Reese TG, Nelissen K, et al. Early time points perfusion imaging. Neuroimage 2011;54(2):1070-1082.

8. Buxton RB. Quantifying CBF with arterial spin labeling. J Magn Reson Imaging 2005;22(6):723-726. 
9. Kimura T, Kusahara H. Reference-based maximum upslope: a CBF quantification $\underline{\text { method without using arterial input function in dynamic susceptibility contrast }}$

10. Miles KA. Perfusion CT for the assessment of tumour vascularity: which protocol? Br J Radiol 2003;76 Spec No 1:S36-42.

11. Kwong KK, Chesler DA. Early time points perfusion imaging: theoretical analysis of correction factors for relative cerebral blood flow estimation given local arterial input function. Neuroimage 2011;57(1):182-189.

12. Kwong KK, Wu O, Chan ST, Nelissen K, Kholodov M, Chesler DA. Early time points perfusion imaging: relative time of arrival, maximum derivatives and fractional derivatives. Neuroimage 2011;57(3):979-990.

13. Larsson HB, Hansen AE, Berg HK, Rostrup E, Haraldseth O. Dynamic contrastenhanced quantitative perfusion measurement of the brain using T1-weighted $\underline{\text { MRI at 3T. J Magn Reson Imaging 2008;27(4):754-762. }}$

14. Li KL, Buonaccorsi G, Thompson G, et al. An improved coverage and spatial $\underline{\text { resolution--using dual injection dynamic contrast-enhanced (ICE-DICE) MRI: a }}$ $\underline{\text { novel dynamic contrast-enhanced technique for cerebral tumors. Magn Reson }}$ $\underline{\text { Med 2012;68(2):452-462. }}$

15. Moonen C, Liu G, Van Gelderen P, Sobering G. A fast gradient-recalled MRI $\underline{\text { technique with increased sensitivity to dynamic susceptibility effects. Mag Res }}$ Med 1992;26:184-189.

16. Ashburner J, Friston K. Multimodal image coregistration and partitioning--a unified framework. Neuroimage 1997;6(3):209-217. 
17. Konig M. Brain perfusion CT in acute stroke: current status. Eur J Radiol 2003;45 Supp1 1:S11-22.

18. Li KL, Zhu X, Zhao S, Jackson A. Blood-brain barrier permeability of normalappearing white matter in patients with vestibular schwannoma: A new hybrid approach for analysis of T1 -W DCE-MRI. J Magn Reson Imaging $\underline{2017 ; 46(1): 79-93 .}$

19. Zhu XP, Li KL, Kamaly-Asl ID, et al. Quantification of endothelial permeability, leakage space, and blood volume in brain tumors using combined T1 and T2* contrast-enhanced dynamic MR imaging. J Magn Reson Imaging 2000;11(6):575$\underline{585 .}$

20. Ostergaard L. Principles of cerebral perfusion imaging by bolus tracking. J Magn $\underline{\text { Reson Imaging 2005;22(6):710-717. }}$

21. Larsson HB, Courivaud F, Rostrup E, Hansen AE. Measurement of brain perfusion, blood volume, and blood-brain barrier permeability, using dynamic contrast-enhanced T(1)-weighted MRI at 3 tesla. Magn Reson Med $\underline{2009 ; 62(5): 1270-1281 .}$

22. Tofts PS. Modeling tracer kinetics in dynamic Gd-DTPA MR imaging. J Magn $\underline{\text { Reson Imaging 1997;7(1):91-101. }}$

23. Fritz-Hansen T, Rostrup E, Sondergaard L, Ring PB, Amtorp O, Larsson HB. Capillary transfer constant of Gd-DTPA in the myocardium at rest and during vasodilation assessed by MRI. Magn Reson Med 1998;40(6):922-929. 
24. Jahng GH, Song E, Zhu XP, Matson GB, Weiner MW, Schuff N. Human brain: $\underline{\text { reliability and reproducibility of pulsed arterial spin-labeling perfusion MR }}$ imaging. Radiology 2005;234(3):909-916.

25. Waterton JC, Solloway S, Foster JE, et al. Diurnal variation in the femoral $\underline{\text { articular cartilage of the knee in young adult humans. Magn Reson Med }}$ $\underline{2000 ; 43(1): 126-132 .}$

26. Wu O, Ostergaard L, Koroshetz WJ, et al. Effects of tracer arrival time on flow estimates in MR perfusion-weighted imaging. Magn Reson Med 2003;50(4):856$\underline{864}$.

27. Rostrup E, Knudsen GM, Law I, Holm S, Larsson HB, Paulson OB. The relationship between cerebral blood flow and volume in humans. Neuroimage 2005;24(1):1-11.

28. Shin JH, Lee HK, Kwun BD, et al. Using relative cerebral blood flow and volume to evaluate the histopathologic grade of cerebral gliomas: preliminary results. AJR Am J Roentgenol 2002;179(3):783-789.

29. Grubb RL, Jr., Raichle ME, Eichling JO, Ter-Pogossian MM. The effects of $\underline{\text { changes in } \mathrm{PaCO} 2 \text { on cerebral blood volume, blood flow, and vascular mean }}$ transit time. Stroke 1974;5(5):630-639.

30. Bruening R, Kwong KK, Vevea MJ, et al. Echo-planar MR determination of relative cerebral blood volume in human brain tumors: T1 versus T2 weighting. AJNR AmJNeuroradiol 1996;17(5):831-840. 
31. Bleeker EJ, van Buchem MA, van Osch MJ. Optimal location for arterial input function measurements near the middle cerebral artery in first-pass perfusion MRI. J Cereb Blood Flow Metab 2009;29(4):840-852.

32. Haroon HA, Patankar TF, Zhu XP, et al. Comparison of cerebral blood volume $\underline{\text { maps generated from T2* and T1 weighted MRI data in intra-axial cerebral }}$ tumours. Br J Radiol 2007;80(951):161-168.

33. Alcaide-Leon P, Pareto D, Martinez-Saez E, Auger C, Bharatha A, Rovira A. Pixel-by-Pixel Comparison of Volume Transfer Constant and Estimates of $\underline{\text { Cerebral Blood Volume from Dynamic Contrast-Enhanced and Dynamic }}$ $\underline{\text { Susceptibility Contrast-Enhanced MR Imaging in High-Grade Gliomas. AJNR }}$ Am J Neuroradiol 2015;36(5):871-876.

34. Carroll TJ, Teneggi V, Jobin M, et al. Absolute quantification of cerebral blood flow with magnetic resonance, reproducibility of the method, and comparison $\underline{\text { with } \mathrm{H} 2(15) \mathrm{O} \text { positron emission tomography. J Cereb Blood Flow Metab }}$ $\underline{2002 ; 22(9): 1149-1156 .}$

35. Larsson HB, Rosenbaum S, Fritz-Hansen T. Quantification of the effect of water exchange in dynamic contrast MRI perfusion measurements in the brain and heart. Magn ResonMed 2001;46(2):272-281.

36. Li K, Djoukhadar I, Zhu X, et al. Vascular biomarkers derived from dynamic contrast-enhanced MRI predict response of vestibular schwannoma to antiangiogenic therapy in type 2 neurofibromatosis. Neuro Oncol 2015. 
37. Sourbron S, Ingrisch M, Siefert A, Reiser M, Herrmann K. Quantification of cerebral blood flow, cerebral blood volume, and blood-brain-barrier leakage with DCE-MRI. Magn Reson Med 2009;62(1):205-217.

38. McDonald RJ, McDonald JS, Newhouse JH, Davenport MS. Controversies in Contrast Material-induced Acute Kidney Injury: Closing in on the Truth?

Radiology 2015;277(3):627-632.

39. Kanal E, Tweedle MF. Residual or retained gadolinium: practical implications for radiologists and our patients. Radiology 2015;275(3):630-634.

40. McDonald RJ, McDonald JS, Kallmes DF, et al. Gadolinium Deposition in $\underline{\text { Human Brain Tissues after Contrast-enhanced MR Imaging in Adult Patients }}$ without Intracranial Abnormalities. Radiology 2017:161595. 
Table 1.

ROI mean values of $\mathrm{CBF}$ measured from the patient with $\mathrm{GBM}$ using different $\mathrm{CBF}$ calculation methods. MRI data were acquired on a 3.0T scanner.

\begin{tabular}{|c|c|c|c|c|c|}
\hline acquisition & analysis method & $\begin{array}{c}\mathrm{CBF}_{\mathrm{GM}} \\
(\mathrm{ml} / \mathrm{min} / 100 \mathrm{ml})\end{array}$ & $\begin{array}{c}\mathrm{CBF}_{\mathrm{WM}} \\
(\mathrm{ml} / \mathrm{min} / 100 \mathrm{ml})\end{array}$ & $\mathrm{CBF}_{\mathrm{GM}} / \mathrm{CBF}_{\mathrm{WM}}$ & $\begin{array}{c}\mathrm{CBF} \text { of tumor } \\
(\mathrm{ml} / \mathrm{min} / 100 \mathrm{ml})\end{array}$ \\
\hline $\mathrm{T} / \mathrm{W}-\mathrm{DCE}$ & $\mathrm{ACcomb}$ & $75.3 \pm 64.6$ & $32.3 \pm 22.8$ & 2.33 & $96.0 \pm 52.9$ \\
\hline & ACrMG & $72.5 \pm 56.7$ & $33.5 \pm 21.9$ & 2.16 & $88.4 \pm 48.5$ \\
\hline & ACrPK & $78.2 \pm 66.2$ & $31.1 \pm 24.9$ & 2.52 & $103.7 \pm 39.5$ \\
\hline & classicalMG. & $180.1 \pm 64.6$ & $128.9 \pm 22.8$ & 1.39 & $194.4 \pm 52.9$ \\
\hline & upslope & $110.3 \pm 83.4$ & $47.7 \pm 36.6$ & 2.31 & $129.7 \pm 79.2$ \\
\hline T2*W-DSC & SVD & $71.5 \pm 66.6$ & $36.7 \pm 26.9$ & 1.95 & $111.0 \pm 75.6$ \\
\hline T1W-DCE & SVD & $76.3 \pm 78.5$ & $37.5 \pm 27.1$ & 2.01 & $130.7 \pm 69.8$ \\
\hline
\end{tabular}


Table 2.

Reproducibility (CoV) of absolute CBF measured in NAWM and NAGM with the ACcomb method. Mean CBF values were calculated using ROIs at $1.5 \mathrm{~T}$ scanner.

\begin{tabular}{|c|c|c|c|c|c|c|c|c|}
\hline \multicolumn{3}{|c|}{ Patient with sporadic VS } & \multicolumn{3}{|c|}{$\begin{array}{c}\text { NAWM } \\
\text { F (ml/min/100ml) }\end{array}$} & \multicolumn{3}{|c|}{$\begin{array}{c}\text { NAGM } \\
\text { CBF }(\mathrm{ml} / \mathrm{min} / \mathbf{1 0 0 m l})\end{array}$} \\
\hline No. & Age (y) & Sex & Visit 1 & Visit 2 & $\mathrm{CoV}$ & Visit 1 & Visit 2 & $\mathrm{CoV}$ \\
\hline 1 & 67 & M & 31.97 & 31.18 & 1.78 & 77.09 & 72.80 & 4.06 \\
\hline 2 & 77 & M & 16.43 & 15.63 & 3.57 & 39.30 & 32.42 & 13.56 \\
\hline 3 & 54 & $\mathrm{M}$ & 28.08 & 25.80 & 5.97 & 60.52 & 60.10 & 0.49 \\
\hline 4 & 69 & M & 25.31 & 25.31 & 0.01 & 51.35 & 55.37 & 5.33 \\
\hline 5 & 67 & $\mathrm{M}$ & 22.99 & 24.52 & 4.58 & 49.45 & 51.60 & 3.02 \\
\hline 6 & 37 & $\mathrm{M}$ & 26.32 & 31.35 & 12.33 & 47.01 & 56.00 & 12.34 \\
\hline 7 & 65 & $\mathrm{M}$ & 23.14 & 24.05 & 2.74 & 42.80 & 49.86 & 10.78 \\
\hline \multicolumn{3}{|c|}{ Mean $\mathrm{CoV} \pm \mathrm{SD}$} & \multicolumn{3}{|c|}{$4.43 \pm 3.98$} & \multicolumn{3}{|c|}{$7.08 \pm 5.09$} \\
\hline \multicolumn{3}{|c|}{ Overall CoV } & \multicolumn{3}{|c|}{5.76} & \multicolumn{3}{|c|}{8.51} \\
\hline
\end{tabular}


Table 3.

Comparison of group mean $\mathrm{CBF}(\mathrm{ml} / \mathrm{min} / 100 \mathrm{ml})$ between day0 and day90 in GM, WM, and $\mathrm{CBF}_{\mathrm{GM}} / \mathrm{CBF}_{\mathrm{WM}}$ in 12 patients with $\mathrm{NF} 2$, estimated using different methods. MRI data were acquired on a $1.5 \mathrm{~T}$ scanner. $P$-values from paired two-tailed t-tests $(\mathrm{df}=11)$ were listed for each paired data.

\begin{tabular}{|c|c|c|c|c|c|c|c|c|c|c|}
\hline \multirow[b]{2}{*}{ methods } & \multirow{2}{*}{$\begin{array}{l}\text { tissue } \\
\text { CBF }\end{array}$} & \multicolumn{3}{|c|}{$\mathrm{CBF}_{\mathrm{GM}}$} & \multicolumn{3}{|c|}{$\mathrm{CBF}_{\mathrm{WM}}$} & \multicolumn{3}{|c|}{$\mathrm{CBF}_{\mathrm{GM}} / \mathrm{CBF}_{\mathrm{WM}}$} \\
\hline & & day0 & day90 & $P$-value & day0 & day90 & $P$-value & day0 & day90 & $P$-value \\
\hline $\mathrm{ACcomb}$ & $\begin{array}{l}\text { mean } \\
\pm \mathrm{SD}\end{array}$ & $\begin{array}{r}55.90 \\
\pm 13.92\end{array}$ & $\begin{array}{r}61.00 \\
\pm 8.28\end{array}$ & 0.093 & $\begin{array}{r}25.83 \\
\pm 3.45\end{array}$ & $\begin{array}{l}28.43 \\
\pm 3.42\end{array}$ & $0.006 *$ & $\begin{array}{r}2.15 \\
\pm 0.28\end{array}$ & $\begin{array}{r}2.15 \\
\pm 0.18\end{array}$ & 0.978 \\
\hline $\mathrm{ACrMG}$ & $\begin{array}{l}\text { mean } \\
\pm \mathrm{SD}\end{array}$ & $\begin{array}{r}60.85 \\
\pm 17.13\end{array}$ & $\begin{array}{r}67.11 \\
\pm 9.37\end{array}$ & 0.122 & $\begin{array}{r}29.99 \\
\pm 4.36\end{array}$ & $\begin{array}{r}32.97 \\
\pm 4.13\end{array}$ & 0.017 & $\begin{array}{r}2.01 \\
\pm 0.31\end{array}$ & $\begin{array}{r}2.04 \\
\pm 0.17\end{array}$ & 0.667 \\
\hline ACrPK & $\begin{array}{l}\text { mean } \\
\pm \mathrm{SD}\end{array}$ & $\begin{array}{r}50.94 \\
\pm 11.51\end{array}$ & $\begin{array}{r}54.88 \\
\pm 8.04\end{array}$ & 0.094 & $\begin{array}{r}21.67 \\
\pm 3.06\end{array}$ & $\begin{array}{r}23.90 \\
\pm 3.17\end{array}$ & $0.001 *$ & $\begin{array}{r}2.34 \\
\pm 0.28\end{array}$ & $\begin{array}{r}2.30 \\
\pm 0.24\end{array}$ & 0.567 \\
\hline classicalMG & $\begin{array}{l}\text { mean } \\
\pm \mathrm{SD}\end{array}$ & $\begin{array}{r}155.56 \\
\pm 17.15\end{array}$ & $\begin{array}{r}159.50 \\
\pm 35.58\end{array}$ & 0.726 & $\begin{array}{r}128.35 \\
\pm 29.06\end{array}$ & $\begin{array}{r}124.08 \\
\pm 35.23\end{array}$ & 0.721 & $\begin{array}{r}1.25 \\
\pm 0.20\end{array}$ & $\begin{array}{r}1.32 \\
\pm 0.19\end{array}$ & 0.198 \\
\hline upslope & $\begin{array}{l}\text { mean } \\
\pm \mathrm{SD}\end{array}$ & $\begin{array}{r}75.42 \\
\pm 16.60\end{array}$ & $\begin{array}{r}81.33 \\
\pm 16.56\end{array}$ & 0.123 & $\begin{array}{r}36.59 \\
\pm 4.45\end{array}$ & $\begin{array}{r}39.48 \\
\pm 6.18\end{array}$ & 0.136 & $\begin{array}{r}2.07 \\
\pm 0.38\end{array}$ & $\begin{array}{r}2.06 \\
\pm 0.24\end{array}$ & 0.912 \\
\hline
\end{tabular}

* Significant at $P<0.01$ (with Bonferroni correction) 


\section{Figure Legends}

\section{Figure 1:}

Figure 1a shows a diagram of 3D fast field echo (FFE) pulse sequence with $\mathrm{TR} / \mathrm{TE} / \alpha=$ $2.95 \mathrm{~ms} / 0.66 \mathrm{~ms} /\left[2^{\circ}, 8^{\circ}, 15^{\circ}, 20^{\circ}\right]$, used for the LDHT-DCE-MRI. This short TR gradient recalled echo based pulse sequence is embedded with both gradient spoiler and phase cycling for the elimination of the net transverse magnetization. The gradient spoilers are applied along read and slab selection directions. The phase cycling has a phase increment angle of $117^{\circ}$. The $3 \mathrm{D}$ data block covers whole brain without use of a RF prepulse, such as the regional saturation technique (REST) by Philips to achieve minimum TR and maximum temporal resolution.

Figure 1b shows the last frame of a 3D FDHS-DCE $(T=600 \mathrm{~s})$ acquisition (left column), in a patient with neurofibromatosis type 2 with a large right sided vestibular schwannoma (see overlaid tumor mask) and multiple meningiomas. The middle and right columns show the last frame of 3D LDHT-DCE ( $T=300 \mathrm{~s})$ overlaid with the segmented grey matter mask or segmented WM mask respectively.

Figure 1c shows maps of $\mathrm{CBF}_{\mathrm{ACcomb}}$ (top left panel, in $\mathrm{ml} / \mathrm{min} / 100 \mathrm{ml}$ ) and $v_{\mathrm{p}}$ derived from ETM (bottom left panel) in the same patient as shown in Fig 1b. The right column shows maps of $K^{\text {trans }}\left(\mathrm{min}^{-1}\right)$ from LDHT MRI (top) or FDHS MRI (bottom), both derived from the ETM. The LDHT derived $K^{\text {trans }}$ map is free from vessel artifacts, whereas the $K^{\text {trans }}$ map derived from the FDHS showed greater tumor heterogeneity detail thanks to 
the higher spatial resolution but at the expense of vessel artifacts due to the low temporal resolution $(\Delta \mathrm{t}=10 \mathrm{~s})$.

Figure 2. a. Distribution of number of exams with various number of data points on the upslope segment prior to the first pass peak of the measured $C_{\mathrm{b}}(t)$ curves. The bottom row shows the typical $C_{\mathrm{b}}(t)$ curves with upslope data points of 4 (b. acquired from a 16-year old male of $85 \mathrm{~kg}$ body weight), 6 (c. acquired from a 16-year old female of $60 \mathrm{~kg}$ body weight), and 8 (d. acquired from a 25 -year old male of $107 \mathrm{~kg}$ body weight).

Figure 3. Assessment of validity of LDHT-T1W DCE MRI for microsphere CBF analysis ( $a$ and $b$ ), and simulation of the 'theoretical' WM and GM curves for Monte Carlo error analysis (c and d). Fig. 3a shows the integrated input curve, multiplied by $\mathrm{f}_{\mathrm{wm}}$ $=25 \mathrm{ml} / \mathrm{min} / 100 \mathrm{ml}=0.00417 \mathrm{ml} / \mathrm{s} / \mathrm{ml}$, and time-shifted to align with the rising bolus time course of the WM concentration curve. Fig. 3b shows the integrated input curve, multiplied by $\mathrm{f}_{\mathrm{gm}}=60 \mathrm{ml} / \mathrm{min} / 100 \mathrm{ml}=0.01 \mathrm{ml} / \mathrm{s} / \mathrm{ml}$, and time-shifted to align with the rising bolus time course of the GM concentration curve. Figures $3 \mathrm{c}$ and $3 \mathrm{~d}$ showed the simulated WM and GM concentration curves respectively.

Figure 4. PD analysis for absolute CBF estimates using different methods. Mean (4a and $4 c)$ and SD (4b and 4d) of percent deviations for CBF of WM (4a and 4b) and CBF of GM (4c and 4d) calculated from 20,000 Monte Carlo repetitions of fitting individual SItime curves using the ACrMG (green), ACrPK (blue), ACcomb (red), upslope (black) and the traditional MG (purple) methods. 
Figure 5. SI curves for representative voxels in GM and WM and for a ROI of a relevant size together with the vascular input function: a) a pixel GM SI-time curve; b) a pixel WM SI-time curve; c) GM (filled square) and WM (circle) ROIs; d) mean SI curve from the GM ROI; e) mean SI curve from the WM ROI; f) vascular input function measured from the superior sagittal sinus. The dashed line in each plot indicates the estimated time of bolus arrival for global AIF.

Figure 6. Figure 6a shows visual comparison of CBF images obtained-at $3 \mathrm{~T}$ from a patient with a glioblastoma multiforme on a $3 \mathrm{~T}$ scanner. The left five columns show CBF images from the LDHT T1W DCE MRI calculated with the five ET methods. The right column shows 3D-CBF from T2*W DSC MRI calculated with a deconvolution method. Figure $6 \mathrm{~b}$ shows the $v_{\mathrm{p}}$ map derived from ETM (left panel), and the T2*W-CBV map (right panel) from the same patient. The 2 nd panel from left shows the intratumoral pixelby-pixel comparison of $v_{\mathrm{p}}$ and $\mathrm{CBF}_{\mathrm{AC} \text { comb }}$, both obtained from the LDHT T1W-DCE MRI, while the $2^{\text {nd }}$ panel from right shows the intratumoral pixel-by-pixel comparison of CBV and CBF derived by SVD-deconvolution, both from the T2*W-DSC MRI.

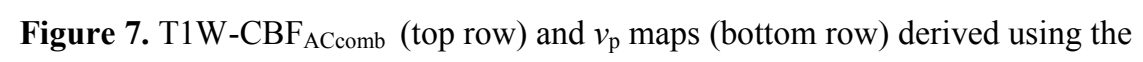
extended Tofts model in an NF2 patient with a large left sided vestibular schwannoma and multiple meningiomas. These maps were derived from the low dose T1W DCE-MRI acquired on a $1.5 \mathrm{~T}$ scanner, pre- and 90 days post- bevacizumab therapy. Slices from three levels of the 3D maps of CBF and $v_{p}$ are displayed, which show: a vestibular 
schwannoma within the left cerebellopontine angle (left two columns, white arrow); a representative slice at the level of the centrum semiovale (middle two columns); and a right sided occipitoparietal meningioma (right two columns, white arrow) and the centrum semiovale (midelle two columns). 


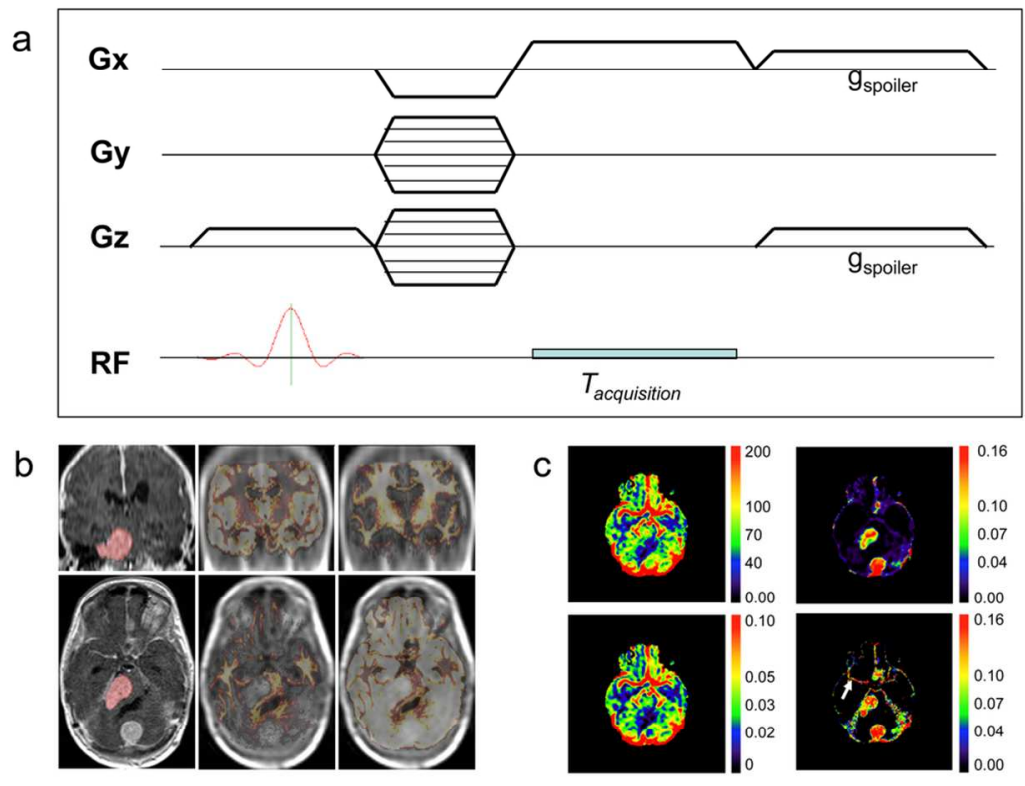

Figure $1 \mathrm{a}$ shows a diagram of 3D fast field echo (FFE) pulse sequence with TR/TE/a $=2.95 \mathrm{~ms} / 0.66 \mathrm{~ms} /\left[2^{\circ}\right.$, $8^{\circ}, 15^{\circ}, 2^{\circ}$ ], used for the LDHT-DCE-MRI. This short TR gradient recalled echo based pulse sequence is embedded with both gradient spoiler and phase cycling for the elimination of the net transverse magnetization. The gradient spoilers are applied along read and slab selection directions. The phase cycling has a phase increment angle of $117^{\circ}$. The $3 \mathrm{D}$ data block covers whole brain without use of a RF prepulse, such as the regional saturation technique (REST) by Philips to achieve minimum TR and maximum temporal resolution.

Figure $1 \mathrm{~b}$ shows the last frame of a 3D FDHS-DCE ( $T=600 \mathrm{~s}$ ) acquisition (left column), in a patient with neurofibromatosis type 2 with a large right sided vestibular schwannoma (see overlaid tumor mask) and multiple meningiomas. The middle and right columns show the last frame of 3D LDHT-DCE $(T=300 \mathrm{~s})$ overlaid with the segmented grey matter mask or segmented WM mask respectively.

Figure 1c shows maps of CBFACcomb (top left panel, in $\mathrm{ml} / \mathrm{min} / 100 \mathrm{ml}$ ) and vp derived from ETM (bottom left panel) in the same patient as shown in Fig $1 \mathrm{~b}$. The right column shows maps of Ktrans (min-1) from LDHT MRI (top) or FDHS MRI (bottom), both derived from the ETM. The LDHT derived Ktrans map is free from vessel artifacts, whereas the Ktrans map derived from the FDHS showed greater tumor heterogeneity detail thanks to the higher spatial resolution but at the expense of vessel artifacts due to the low temporal resolution $(\Delta t=10 \mathrm{~s})$.

$107 \times 76 \mathrm{~mm}(300 \times 300 \mathrm{DPI})$ 
Figure 2. a. Distribution of number of exams with various number of data points on the upslope segment prior to the first pass peak of the measured $\mathrm{Cb}(\mathrm{t})$ curves. The bottom row shows the typical $\mathrm{Cb}(\mathrm{t})$ curves with upslope data points of 4 (b. acquired from a 16-year old male of $85 \mathrm{~kg}$ body weight), 6 (c. acquired from a 16-year old female of $60 \mathrm{~kg}$ body weight), and 8 (d. acquired from a 25-year old male of $107 \mathrm{~kg}$ body weight).

\section{$117 \times 91 \mathrm{~mm}(300 \times 300 \mathrm{DPI})$}



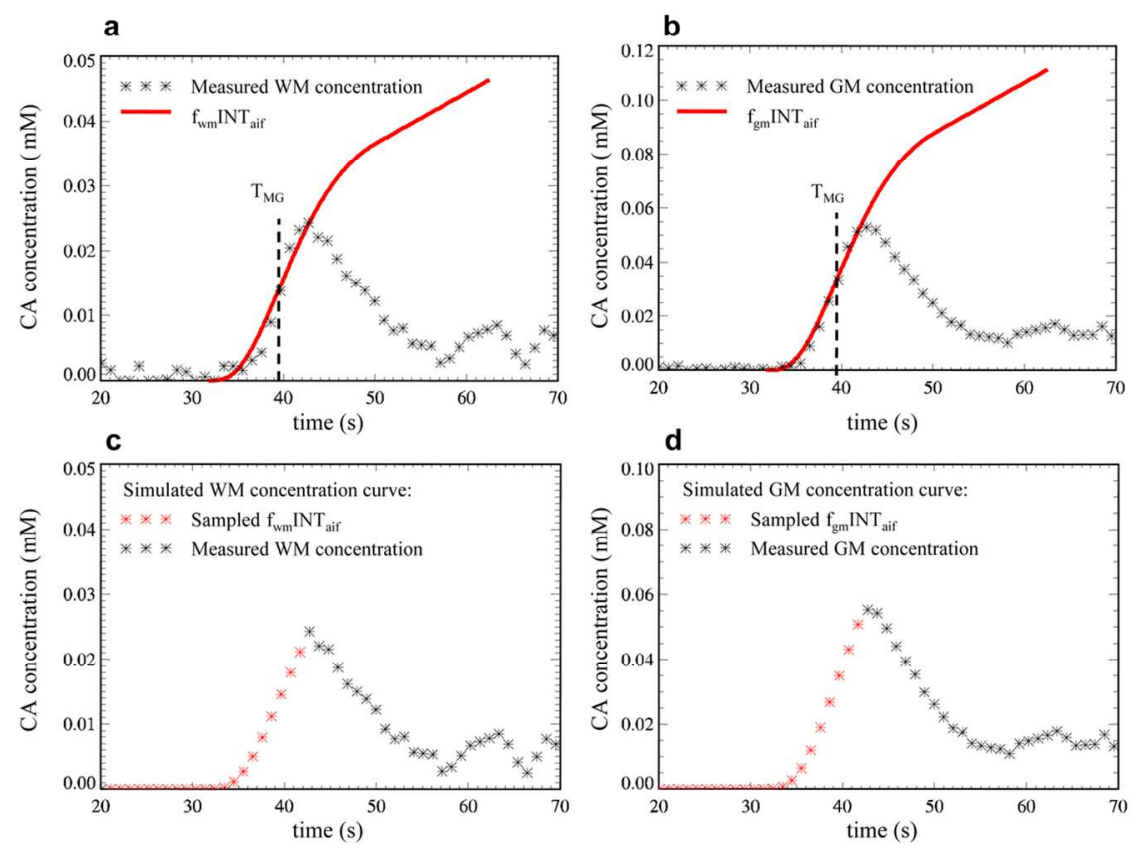

Figure 3. Assessment of validity of LDHT-T1W DCE MRI for microsphere CBF analysis ( $a$ and $b$ ), and simulation of the 'theoretical' WM and GM curves for Monte Carlo error analysis (c and d). Fig. 3a shows the integrated input curve, multiplied by fwm $=25 \mathrm{ml} / \mathrm{min} / 100 \mathrm{ml}=0.00417 \mathrm{ml} / \mathrm{s} / \mathrm{ml}$, and time-shifted to align with the rising bolus time course of the WM concentration curve. Fig. 3b shows the integrated input curve, multiplied by $\mathrm{fgm}=60 \mathrm{ml} / \mathrm{min} / 100 \mathrm{ml}=0.01 \mathrm{ml} / \mathrm{s} / \mathrm{ml}$, and time-shifted to align with the rising bolus time course of the GM concentration curve. Figures $3 c$ and $3 d$ showed the simulated WM and GM concentration curves respectively.

$117 \times 91 \mathrm{~mm}(300 \times 300 \mathrm{DPI})$ 

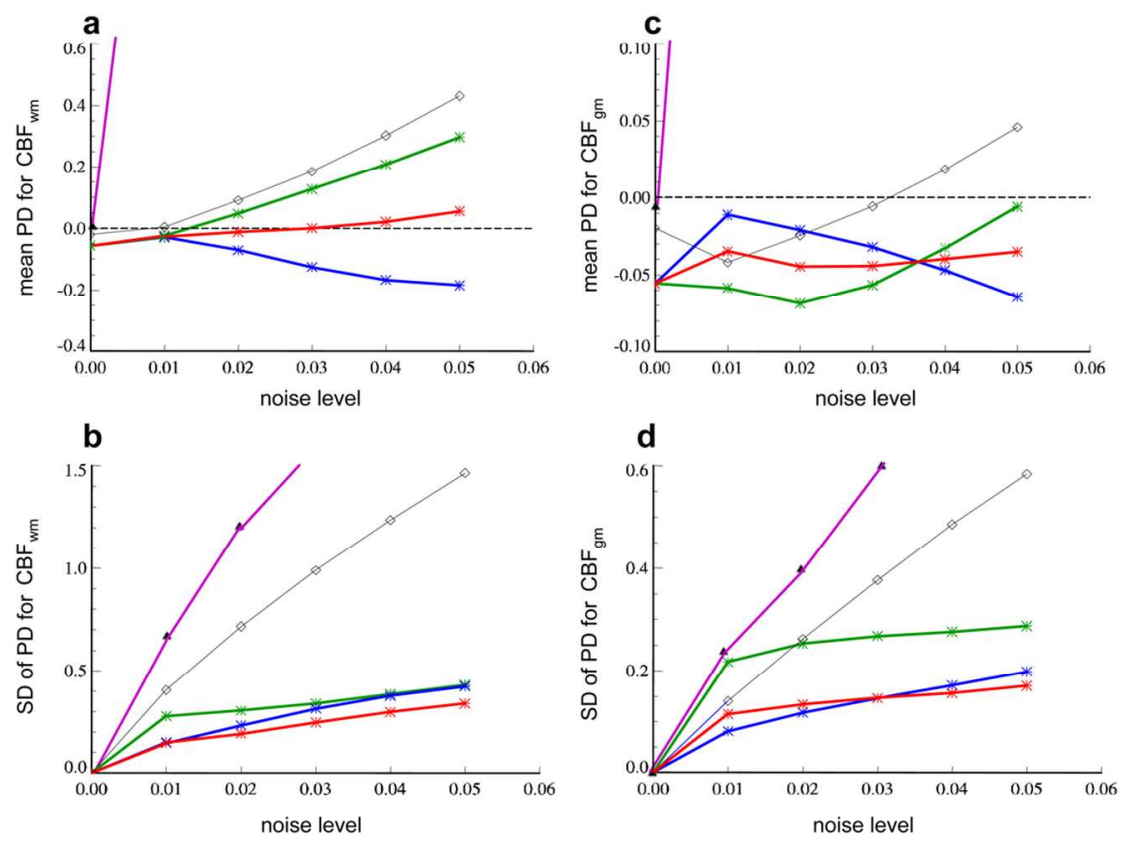

Figure 4. PD analysis for absolute CBF estimates using different methods. Mean (4a and 4c) and SD (4b and $4 d$ ) of percent deviations for CBF of WM (4a and $4 b$ ) and CBF of GM (4c and $4 d$ ) calculated from 20,000 Monte Carlo repetitions of fitting individual SI-time curves using the ACrMG (green), ACrPK (blue), ACcomb (red), upslope (black) and the traditional MG (purple) methods.

$117 \times 91 \mathrm{~mm}(300 \times 300 \mathrm{DPI})$ 


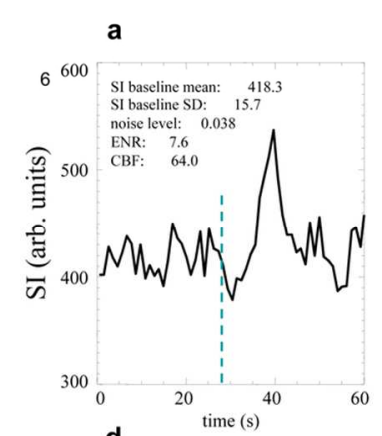

\section{b}

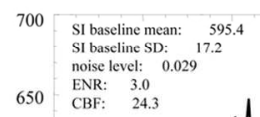

650 CBF: 24.

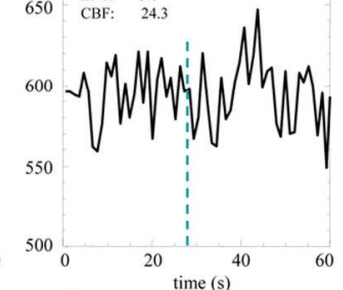

c
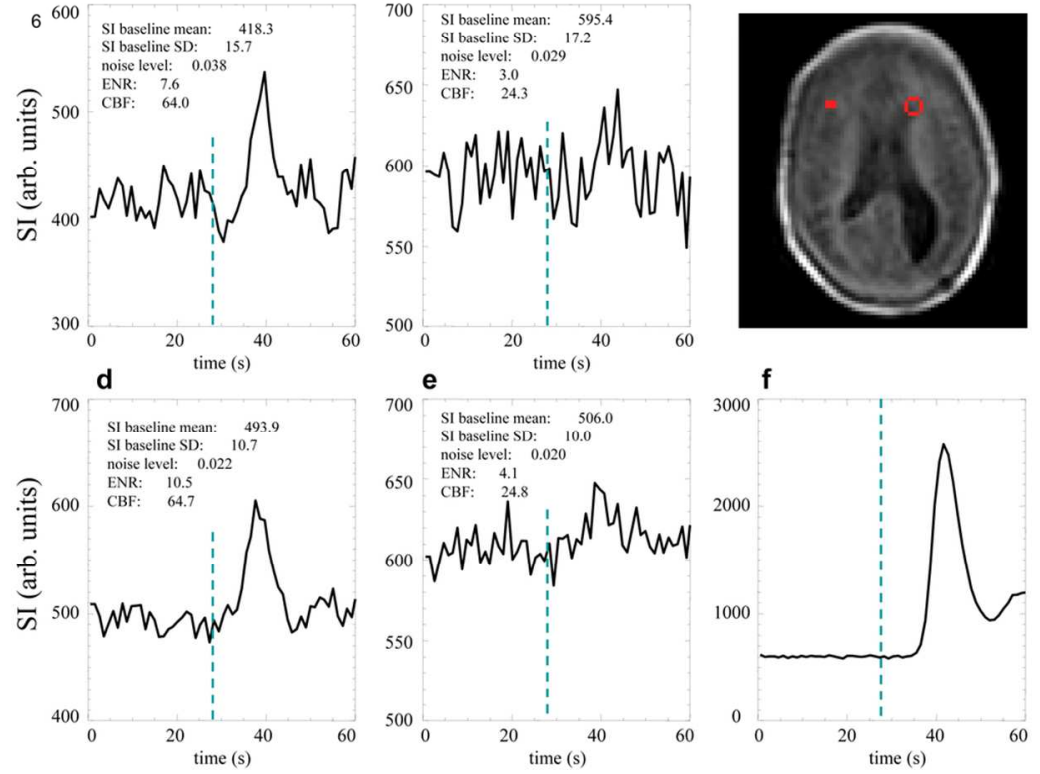

Figure 5. SI curves for representative voxels in GM and WM and for a ROI of a relevant size together with the vascular input function: a) a pixel GM SI-time curve; b) a pixel WM SI-time curve; c) GM (filled square) and WM (circle) ROIs; d) mean SI curve from the GM ROI; e) mean SI curve from the WM ROI; f) vascular input function measured from the superior sagittal sinus. The dashed line in each plot indicates the estimated time of bolus arrival for global AIF.

$107 \times 76 \mathrm{~mm}(300 \times 300 \mathrm{DPI})$ 
Figure 6. Figure 6a shows visual comparison of CBF images obtained from a patient with a glioblastoma multiforme on a 3T scanner. The left five columns show CBF images from the LDHT T1W DCE MRI calculated with the five ET methods. The right column shows CBF from T2*W DSC MRI calculated with a deconvolution method.

Figure $6 \mathrm{~b}$ shows the vp map derived from ETM (left panel), and the T2*W-CBV map (right panel) from the same patient. The 2 nd panel from left shows the intratumoral pixel-by-pixel comparison of vp and CBFACcomb, both obtained from the LDHT T1W-DCE MRI, while the 2nd panel from right shows the intratumoral pixel-by-pixel comparison of CBV and CBF derived by SVD-deconvolution, both from the T2*WDSC MRI.

$107 \times 76 \mathrm{~mm}(300 \times 300 \mathrm{DPI})$ 
Figure 7. T1W-CBFACcomb (top row) and vp maps (bottom row) derived using the extended Tofts model in an NF2 patient with a large left sided vestibular schwannoma and multiple meningiomas. These maps were derived from the low dose T1W DCE-MRI acquired on a 1.5T scanner, pre- and 90 days post- bevacizumab therapy. Slices from three levels of the 3D maps of CBF and vp are displayed, which show: a vestibular schwannoma within the left cerebellopontine angle (left two columns, white arrow); a representative slice at the level of the centrum semiovale (middle two columns); and a right sided occipitoparietal meningioma (right two columns, white arrow).

$107 \times 76 \mathrm{~mm}(300 \times 300 \mathrm{DPI})$ 